\title{
Evaluation of Feeds for Melt and Dilute Process Using an Analytical Hierarchy Process
}

by

J. F. Krupa

Westinghouse Savannah River Company

Savannah River Site

Aiken, South Carolina 29808

H. Peacock

W. Bickford

H. Brooks

W. Swift

T. Adams

DOE Contract No. DE-AC09-96SR18500

This paper was prepared in connection with work done under the above contract number with the U.S.

Department of Energy. By acceptance of this paper, the publisher and/or recipient acknowledges the U.S.

Government's right to retain a nonexclusive, royalty-free license in and to any copyright covering this paper, along with the right to reproduce and to authorize others to reproduce all or part of the copyrighted paper. 


\section{EVALUATION OF FEEDS FOR MELT AND DILUTE PROCESS USING AN ANALYTICAL HIERARCHY PROCESS (U)}

- February 2000

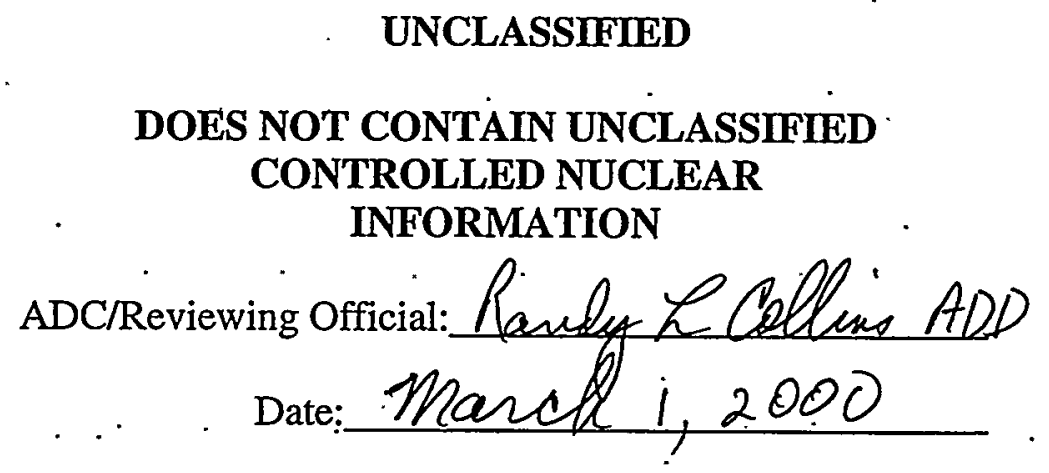

Westinghouse Savannah River Company Savannah River Site Aiken, SC 29808 


\section{DISCLATMER}

This report was prepared as an account of work sponsored by an agency of the United States Government. Neither the United States Government nor any agency thereof, nor any of their employees, makes any warranty, express or implied, or assumes any legal liability or responsibility for the accuracy, completeness, or usefulness of any information, apparatus, product or process disclosed, or represents that its use would not infringe privately owned rights. Reference herein to any specific commercial product, process or service by trade name, trademark, manufacturer, or otherwise does not necessarily constitute or imply its endorsement, recommendation, or favoring by the United States Government or any agency thereof. The views and opinions of authors expressed herein do not necessarily state or reflect those of the United States Government or any agency thereof.

This report has been reproduced directly from the best available copy.

Available for sale to the public, in paper, from: U.S. Department of Commerce, National Technical Information Service, 5285 Port Royal Road, Springfield, VA 22161, phone: (800) 553-6847

fax: (703) 605-6900

email: orders@ntis.fedworld.gov

online ordering: http://www.ntis.gov/ordering.htm

Available electronically at http://www.doe.gov/bridge

Available for a processing fee to U.S. Department of Energy and its contractors, in paper, from: U.S. Department of Energy, Office of Scientific and Technical Information, P.O. Box 62, Oak Ridge, TN 37831-0062, phone: (865) 576-8401

fax: (865) $576-5728$

email: reports@adonis.osti.gov 


\section{DISCLAIMER}

Portions of this document may be illegible in electronic image products. Images are produced from the best available original document. 


\section{EVALUATION OF FEEDS FOR MELT AND DILUTE PROCESS USING AN ANALYTICAL HIERARCHY PROCESS (U)}

SITEWIDE INTEGRATION \& PROGRAM DEVELOPMENT DIVISION:

AQUTHOR: : J. F. KRUPA

APPROVED BY:

R. E. MEADORS, MANAGER

STRATEGIC PLANNING AND INTEGRATION DEPARTMENT

WESTINGHOUSE SAVANNAH RIVER COMPANY

February 2000

Westinghouse Savannah River Company Savannah River Site Aiken, SC 29808 


\section{CONCURRENT SIGNATURES OF TEAM MEMBERS}

Harold Peacock, Ph.D.

Advisory Engineer

Materials Application and

Corrosion

Techriology

Savannah River Technọlogy

Center

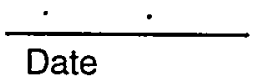

Date

Helen Brooks

Program Manager,

Alternative Technologies

Spent Fuel Storage Division
Date

Principal Technical Advisor,

Strategic Planning and

Integration

Sitewide Integration \&

Program Development

Division

\section{Wade E. Bickford}

Senior'Advisory Engineer

Strategic Planning and

Integration

Sitewide Integration \&

Program Development

Division

\section{Date}

Thad Adams, Ph.D.

Senior-Engineer

William F. Swift

Manager, Alternative

Technologies

Spent Fuel Storage Division

\section{Date}

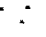

Materials Application and

Corrosion

Technology

Savannah River Technology

Center 


\section{LIST OF ACRONYMS}

AHP

DDIS

DOE

DU

DWPF

EBR

EIS

ES\&H

FRR

HFIR

HLW

LEU.

- LLW .

MGDS

NRC

NWPA

O\&M

PWF

QA

ROD

RRTT

$S \& S$

$\mathrm{SC}$

SNF

SRS

TPC

TSF

WSMS

WSRC
Analytic Hierarchy Process

(Mined Geologic Disposal System) Draft Disposability Interface Specification

Department of Energy

Depleted Uranium

Defense Waste Processing Facility

Experimental Breeder Reactor

Environmental Impact Statement

Envirömmental, Safety, \& Health

Foreign Research Reactor

High Flux Isotope Reactor

High Level Waste

Low Enriched Uränium

:Low Level Waste

Mined Geologic Disposal System

Nuclear Regulatory Commission

Nuclear Waste Policy Act

Operations \& Maintenance

Primary Waste Form

Quality Assurance

Record of Decision

Research Reactor (Spent Nuclear Fuel) Task Team

Safeguards \& Security

South Carolina

Spent Nuclear Fuel

Savannah River Site

Total Project Cost .

Treatment and Storage Facility

Westinghouse Safety Management Solutions

Westinghouse Savannah River Company 


\section{EXECUTIVE SUMMARY}

The Analytical Hierarchy Process using a ratings methodology was used to rank potential feed candidates for disposition through the Melt and Dilute facility proposed for disposition of Savannah River Site aluminum-clad spent nuclear fuel. Because of the scoping nature of this analysis, the expert team convened for this purpose concentrated on technical feasibility and potential cost impacts associated with using melt and dilute versus the current disposition option.

Some of the materials have currently defined disposition paths, however, significant costs are involved in their implementation. A number of plutonium scrap materials were determined to be attractive candidates, for which a significant and costly immobilization program has been developed. Melt and dilute may provide an alternative that meets some expressed concerns about the immobilization waste form, since the plutonium would be homogeneously dispersed throughout the melt and dilute product and thus significant processing and shielding capability would be required to recover plutonium. This : alternative needs additional examination as a potential backup technology that could result in substantial cost avoidance.

Depleted, low enriched, and natural uranium are obvious feeds for the process for use in diluting high enriched to enrichments that are not weapons capable. Melt and dilute is also an obvious alternative for off-spec HEU should current negotiations with TVA reach an impasse.

Finally, the melt and dilute waste form is also a possibility for miscellaneous higher isotopes because of their small quantity.

Figure E-1 illustrates the ratings for the range of recommended candidates. 
Total Ratings Score

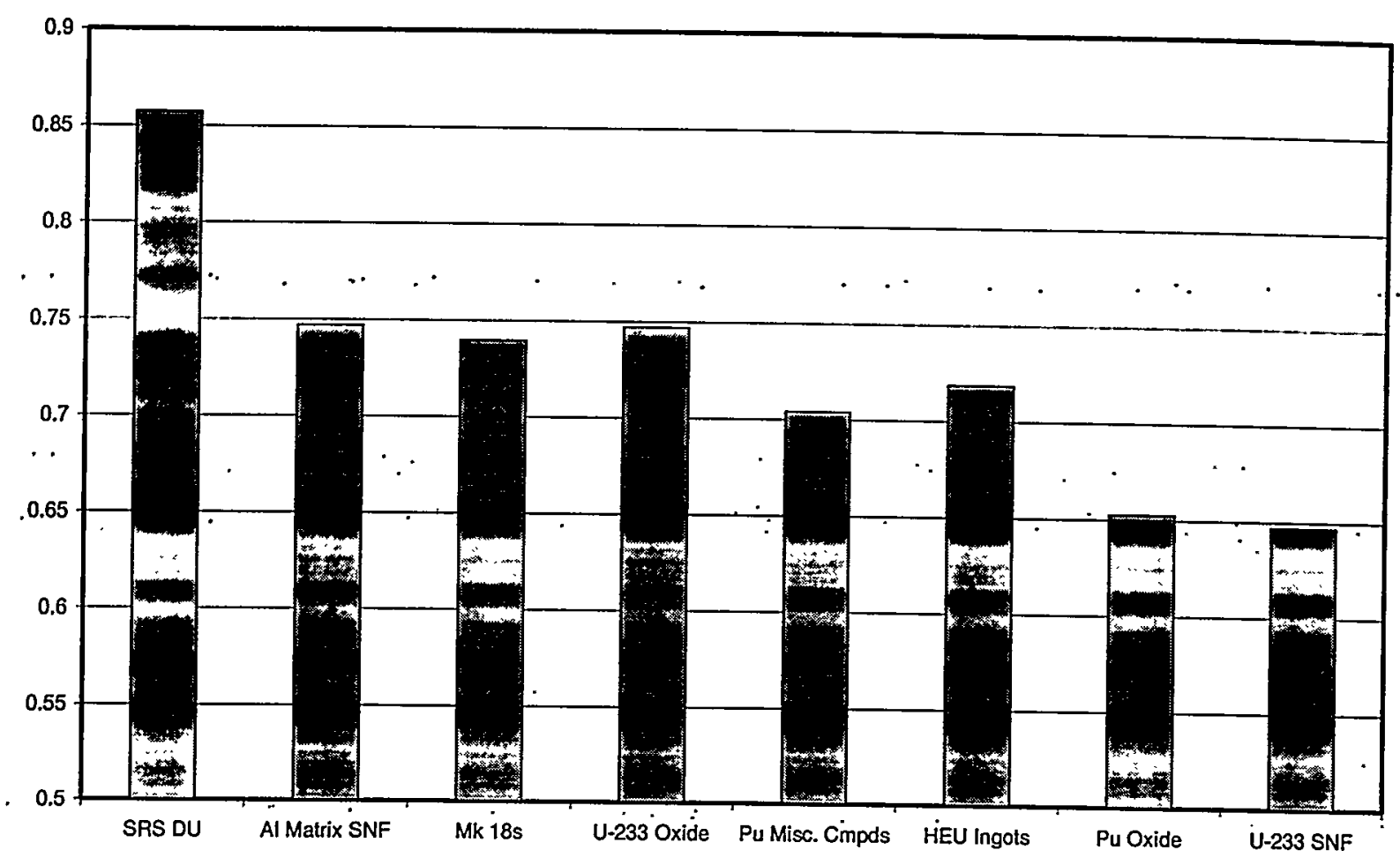

Figure E-1. Ratings of Selected Recommended Candidates 


\section{INTRODUCTION}

\section{Initiation of Task}

WSRC was requested ${ }^{1}$ to evaluate whether nuclear materials other than aluminum-clad spent nuclear fuel should be considered for treatment to prepare them for disposal in the melt and dilute facility as part of the Treatment and Storage Facility (TSF) currently projected for construction in the L-Reactor process area. Spent Fuel Storage Division convened a number of experts on the melt and dilute technology, the TSF project, and nuclear materials at Department of Energy sites to develop an evaluation approach and a path forward. A preliminary evaluation of illustrative candidate materials was determined to be an appropriate first step to respond to this request.

The decision analysis process used to develop this analysis considered many variables and uncertainties, including repository requirements that are not yet finalized. This report documents results of the decision analysis.

\section{Background}

The Record of Decision for the Environmental Impact Statement on the Proposed Nuclear Weapons Nonproliferation Policy Concerning Foreign Research Reactor (FRR) Spent Nuclear Fuel (SNF) directed the DOE to implement alternative treatment and packaging technologies that could be utilized in place of conventional chemical processing to achieve safe and cost effective interim storage and ultimate disposal.

For the last three years, WSRC has been evaluating two candidate SNF disposal methodologies, melt and dilute, and direct disposal, both options being co-disposed with HLW glass canisters as alternatives to conventional processing. In the Spring of 1998, WSRC completed an analysis of the merits of the two technologies at the request of DOE-SR. Based on that analysis, which used an analytical hierarchy process, WSRC recommended that, between these two options, the melt and dilute process be used for aluminum-clad SNF disposition. The description below of the envisioned melt and dilute process is excerpted from that study ${ }^{2}$.

\section{Melt \& Dilute Technology Description}

In the melt and dilute technology, the SNF will be melted in a furnace. Depleted uranium and aluminum (as needed to control the metallurgy and process temperature) will be added to the melt in order to reduce the ${ }^{235} \mathrm{U}$ enrichment to below $20 \%$, the level required to be treated as low enriched uranium (LEU). If required, neutron absorber materials will also be added to the melt to minimize the potential for long-term criticality in the repository. The melt will be solidified and placed in a steel canister. Several ingots may be stacked in each canister. The canister will then be back-filled with helium, sealed, and temporarily stored at SRS in concrete storage modules.

The canisters will ultimately be shipped to a federal geologic repository for final disposal with glass high level waste (HLW) canisters produced in the Defense Waste Processing Facility. The melting process will cause volatilization of some fission products. Those gases will be collected and processed onsite as either HLW or low level waste (LLW), with the exception of minimal quantities of noble gases such as krypton which will be released to the facility stack. A flow diagram of the process is shown in Figure 1. 


\section{Cask Handling Area:}

- Cask receipt, staging, and washdown.

- Cask venting, sampling, and bolt removal.

- Cask transfer to hot cell.

- Cask decontamination stations (2).<smiles>[CH]1[CH]CC1</smiles>

- Unloading Area/Lag Storage:

- Remove cask lid.

- Remove each assembly, can, or basket.

- Attach ID label to assembly or can, and place

in Lag Storage Racks; 500 position capacity.

- Return cask to cask handling area for decon.



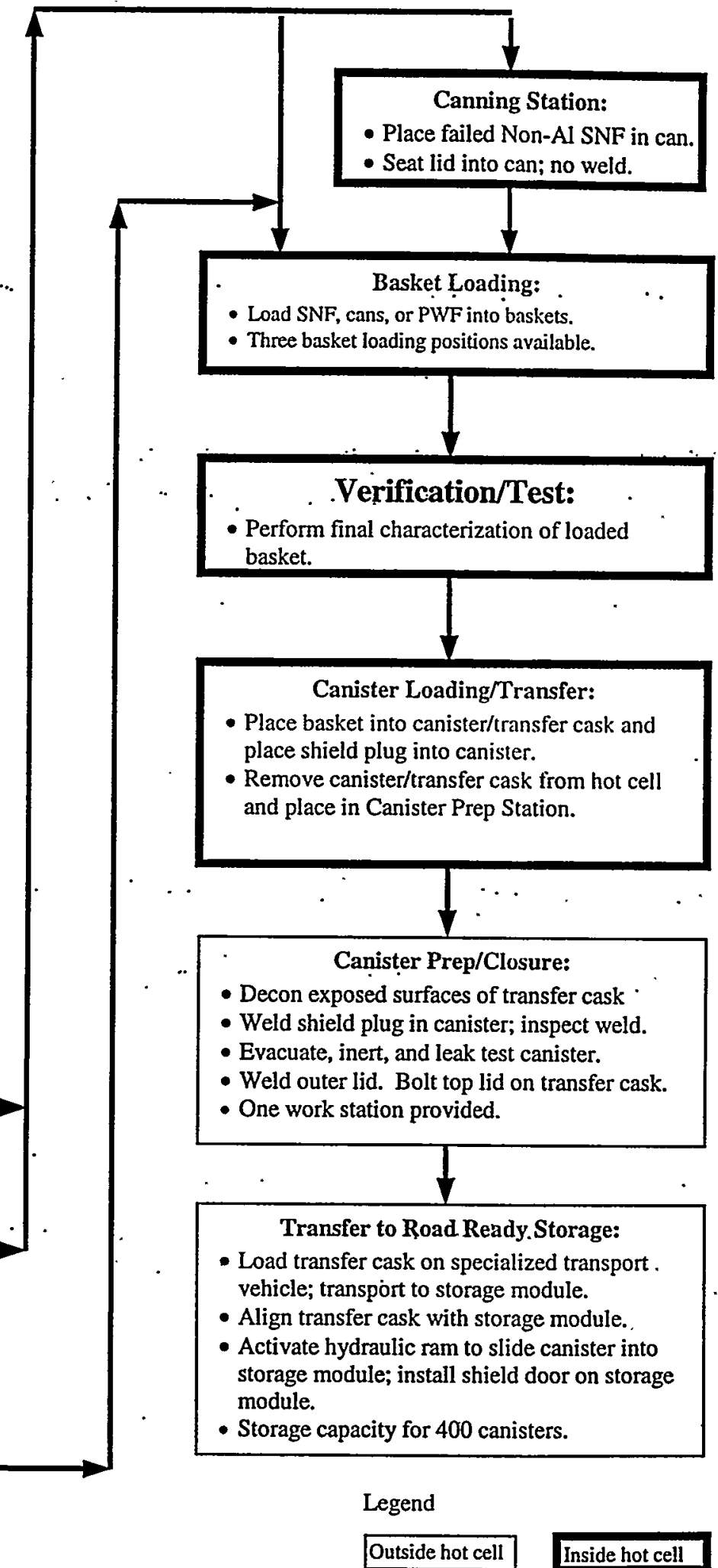

Figure 1. Facility Process Flow Diagram, Melt \& Dilute 


\section{DISCUSSION}

\section{Analytic Hierarchy Process}

The decision process for evaluating the suitability of melt and dilute process facilities for disposition of materials was structured using the Analytic Hierarchy Process (AHP). Expert Choice ${ }^{\mathrm{TM}}$ decision support software, which has as its basis the Analytical Hierarchy Process, was utilized to help record and document the expert rankings developed in this analysis of the application of melt and dilute technology to alternate feed streams. AHP enhances decision making by providing a logical framework in which all elements of a decision can be defined, organized,'and carefully evaluated. AHP as a mathematical methodology for measurement and decision making was developed by Dr. Thomas L. Saaty more than 20 years ago to deal with problems that had both objective and subjective components.

As Dr. Saäty notes in his book Decision Making for Leaders ${ }^{3}$ "In solving problems by explicit logical analysis, three principles can be distinguished: the principle of constructing hierarchies, the principle of establishing priorities, and the principle of logical consistency. These natural principles of analytic thought underlie the AHP." He goes on to say "In utilizing these three principles, the AHP incorporates both the qualitative and the quantitative aspects of human thought: the qualitative to define the problem and its hierarchy, and the quantitative to express judgments and preferences concisely. The process itself is designed to integrate these two properties."

The AHP depends on imagination, experience, and knowledge to structure the hierarchy of a problem and on logic, intuition, and experience to provide judgments. It provides a framework for connecting elements of one part of a problem with those of another to obtain the combined outcome. AHP provides a process for identifying, understanding, and assessing the interactions of a system as a whole.

Most people cannot deal with more than seven decision considerations at a time. AHP deals with this cognitive limitation by subdividing the decision into logical groupings of decision criteria in a hierarchy. Influence in this hierarchical structure is distributed downward. The top level, or goal, has the greatest importance (or priority) and thus has a value of one. This value is apportioned among the elements in the second level, and the values of each of these in turn is apportioned among those of the third level, and so-on to the lowest-level objectives/criteria. These objective/criterion priority values are derived by the $\mathrm{ECPro}^{\mathrm{TM}}$ program ${ }^{4}$ based upon pair-wise comparisons of the objectives at each of the model nodes ${ }^{\mathrm{a}}$.

In a situation where there are multiple candidates to be evaluated, like the nuclear materials in this study, the lowest level of the hierarchy is used to develop a rating scale, using pair-comparisons. Candidates are then evaluated as to which description most accurately describes their relationship to the bottom-most criteria. From this, a total score is derived that allows ranking the candidate . materials against the goal of using melt and dilute technology for their disposal.

An important aspect of using the AHP ratings methodology to evaluate materials, was the discussion of attributes and development of consensus among the participants.

\footnotetext{
${ }^{a}$ The elements of a decision are represented by nodes. A node may represent an objective, a criterion, a subcriterion, an uncertainty (scenario), an alternative, (etc.). ECPro $^{\mathrm{TM}}$ for Windows, User Manual page 345.
} 


\section{Creation Of Team}

A team of materials experts from the Savannah River Technology Center, operations and project experts from Spent Fuel Storage Division, and nuclear materials disposition experts from Strategic Planning and Integration Department comprised the evaluation team. Appropriate management input . was solicited during the evaluation as it progressed.

Biographical information for each of the team members is provided in Appendix A.

\section{Assumptions.}

The following assumptions were used during the evaluation.

- An illustrative group of materials would suffice for this evaluation to show proof of principle for the attractiveness of melt and dilute as a disposal path for materials.

- Although health, safety, and the environment are pre-eminent concerns, they wère not included in this analysis because they did not have a differentiating impact on the SNF alternatives decision. Neither WSRC nor DOE intends to build or operate facilities that would have a negative impact on worker or public safety and health or the environment. Rather, these variables would be reflected in costs required to modify the baseline melt and dilute facility to handle new feed materials.

- The impact of Non-governmental Organizations (NGOs) in the Spent Fuel Alternatives study was found not to be decisional in the final analysis. They were not considered in this study.

- Since there is no melt and dilute facility, modifications which might suggest construction of a Greenfield facility rather than use of the L-Reactor Process Building were considered. The impact would be taken up in cost effected criteria.

\section{Decision Objectives}

The overall goal of the study was to select potential candidates for disposal via melt and dilute technology. Using the first basic function of AHP, that of structuring complexity, the team identified a number of primary objectives that, if satisfied, would achieve this goal. To this end, the team agreed that the best candidate materials would meet the following objectives:

1. Be most compatible with the melt and dilute process as it is currently conceived;

2. Result in a waste form that was acceptable at its ultimate disposition point;

3. Had low implementation cost and high potential programmatic savings;

4. Was compatible with current transportation, packaging, and storage;

5. Required the least amount of technical development for the process and the final waste form.

With these primary objectives in mind, the team then identified 17 supporting decision criteria against which the candidate materials could be evaluated. These elements were then organized into a hierarchy structure that formed the basis for the team's decision analysis model. 


\section{Criteria Descriptions}

The 17 supporting criteria developed to meet the primary decision objectives are provided below. For each of the criteria considered and selected for inclusion in the decision analysis model, a 'Criterion Definition' is provided along with justification for its inclusion. 'Criterion Definitions' were also developed for each of the five primary decision objectives to facilitate the generation of supporting decision criteria. The overall assessment of the importance of the five primary objectives is shown below in Figure 2. Note that an inconsistency ratio below 0.1 indicates an adequately consistent set of pair-wise comparișons.

\section{Develop a ratings for attractiveness for using melt and dilute.}

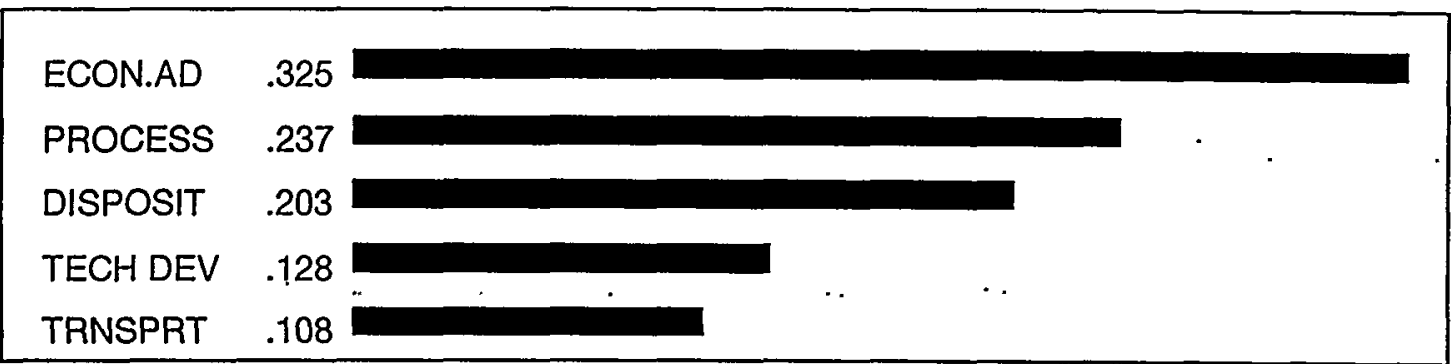

Inconsistency Ratio $=0.06$

\begin{tabular}{|l|l|}
\hline Abbreviation & \\
Goal & Develop a ratings for attractiveness for using melt and dilute \\
ECON.AD & Potential for savings \\
PROCESS & Disposition process compatability with M\&D \\
DISPOSIT & Compatability of waste form with Yucca, WIPP, LLW etc. \\
TECH DEV & Technology Development Required \\
TRNSPRT & Ability to ship and receive \\
\hline
\end{tabular}

Figure 2. Summary Importance of the Five Evaluation Criteria 


\section{Compatibility with Melt and Dilute}

Material attractiveness was considered to be affected by the degree which they could be accommodated in the proposed melt and dilute facility (either as envisaged in the L-Reactor process room or in a new Greenfield facility). Criteria that contributed to material attractiveness included the following:

1. Feed composition. Materials whose composition was well known was judged to be more attractive than materials with less well characterized or unknown provenance. Poorly characterized materials would require characterization before introduction into the process with concomitant increase in cost and/or dose to personnel.

2. Temperature. Materials that could be processed at or below the currently planned $850^{\circ} \mathrm{C}$ operating temperature were judged to be more attractive than maferials which required higher temperatures to successfully prepare for disposition.

3. Off-gas Requirements. Materials which had the same or lower (because of low volatile fission product inventory, e.g., iodine-129 or cesium-137) were judged as more attractive than those which had higher volatile fission product content.

4. Material Compatibilities. Those materials that could be treated in a steel crucible were considered to be more attractive for melt and dilute processing than those that required more exotic types of crucibles.

5. Alloy Composition. Those materials whose disposition alloy was similar to the eutectic U/Al alloy proposed for melt and dilute were judged to be more attractive than more complex materials that required new or yet to be determined alloys for effective disposition.

6. Pretreatment Requirements. Some materials would require pretreatment before introduction into the melt and dilute system, either size reduction, as in the case of fuel rods or conversion to solids in the case of solution. Lower levels of pretreatment were seen as more attractive.

Compatibility of the Waste Form Produced with Disposition in the Mined Geologic Disposal System (MGDS), WIPP or Burial at the NTSL.

7. Path Availability. Materials with currently defined disposition paths, including an available operating.facility and adequate funding, were seen as less attractive than those where a disposition path was yet to be determined.

8. Attractiveness of Melt and Dilute Wasteform. Material attractiveness for this criteria was determined by the judgement of how difficult it would be to qualify a melt and dilute type of waste form for the proposed disposition site.

\section{Economic Advantage of Disposition Through the Melt and Dilute Facility}

9. Implementation Cost. Those materials which required little in the way of implementation cost, e.g., only operating cost or minimal capital cost, were seen as more attractive than materials that required major capital investment or design alterations for the melt and dilute facility. 
10. Cost Savings. If disposition through melt and dilute would result in a significant capital or operating savings, it was seen to be attractive.

11. Quantity. The quantity of material was a complex criteria. Very small quantities offered the potential of minimal impact on the facility, whereas significant quantities offered the potential of savings through long term continuous operation on a single feed.

Transportation Impacts Including Consideration of the Ease of Shipping, Receiving, Packaging and ..Storage. .

12. Receiving. Availability of facilities for receiving materials made them more attractive for melt and dilute processing.

13. Shipping. Availability of shipping casks or packages and facilities for shipment made materials more attractive:

14. Packaging. If a material was already packaged or ready for shipment, it was seen as more attractive than materials that required packaging.

15. Storage. Material already possessing on-site storage or that required minimal changes to allow storage of the final waste form was seen as more attractive.

\section{Technology Development Required}

16. Processing Development. Material that fit within current processing development or existing processing experience was seen as more attractive than materials that would require additional process development.

17. Waste Form Development. If a materials waste form was bounded by current testing or required . minimal modifications it was seen as more a more attractive candidate.

\section{Summary of Criteria Priorities}

After all objectives and associated criteria were evaluated for importance at each of the model nodes, the overall results were synthesized using the ECPro ${ }^{\mathrm{TM}}$ program. Table 1 below provides a prioritized summary of all objectives/criteria and their relative overall importance (global priority) in selecting the preferred alternative. Note that these data are arranged in the model hierarchy levels, and within those levels, are listed according to the priority of the individual criteria. 


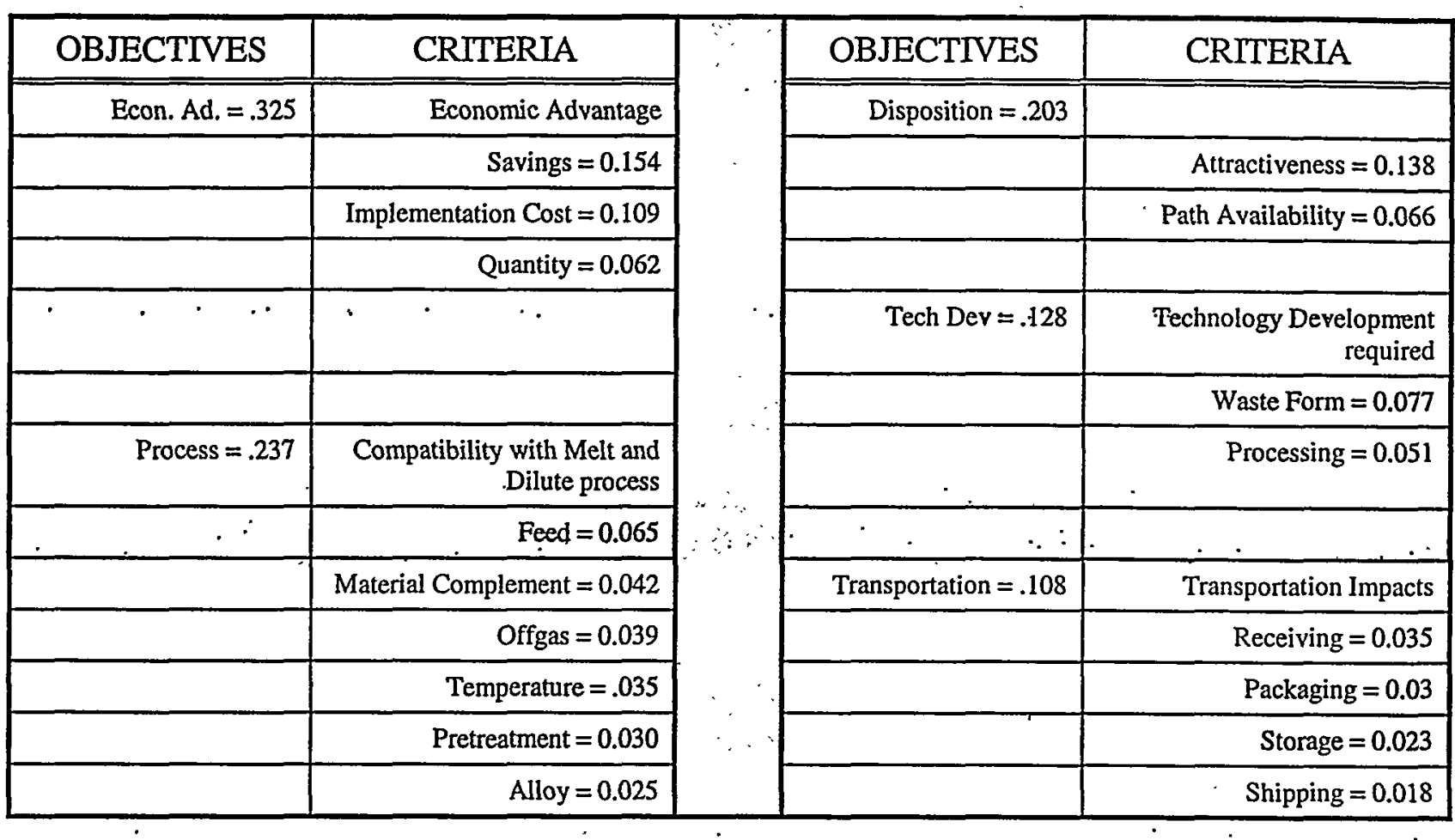

Table 1. Summary of Objective/Criterion Priorities (Global)

Figure 3 below provides a prioritized summary of the overall importance (or global priority) of all of the criteria. This list is significant in that suitability of candidate materials was judged directly against these criteria. Note that economic advantages accounts for about $1 / 3$ of the importance in the . decision, and that the first six criteria (potential for savings, attractiveness of the waste form, implementation cost) account for approximately $61 \%$ of the importance in the determination of the attractiveness of materials for melt and dilute treatment. .

Team scores were developed for each of the criteria by taking the geometric mean of Team responses and calculated the distribution using EC Pro software. The geometric mean was used because it centers on one rather than zero, so that opposite but equal views would cancel out. The geometric mean was also conservative in that it can be shown that the geometric mean is less than or equal to the arithmetic mean, tending to damp out strong responses. Details of the criteria evaluations are given in Appendix B.

\section{Development Of The Ratings Scheme}

In order to use the criteria above for a ratings scheme, a set of descriptors was developed for an ordinal scale for each of the criteria. These descriptors were then pair-wise compared using the Team geometric mean as above and EC Pro software. Details of the ratings evaluation are shown in Appendix C. 


\section{Develop a ratings for attractiveness for using melt and dilute}

\section{Synthesis of Level 2 Nodes with respect to GOAL} Distributive Mode

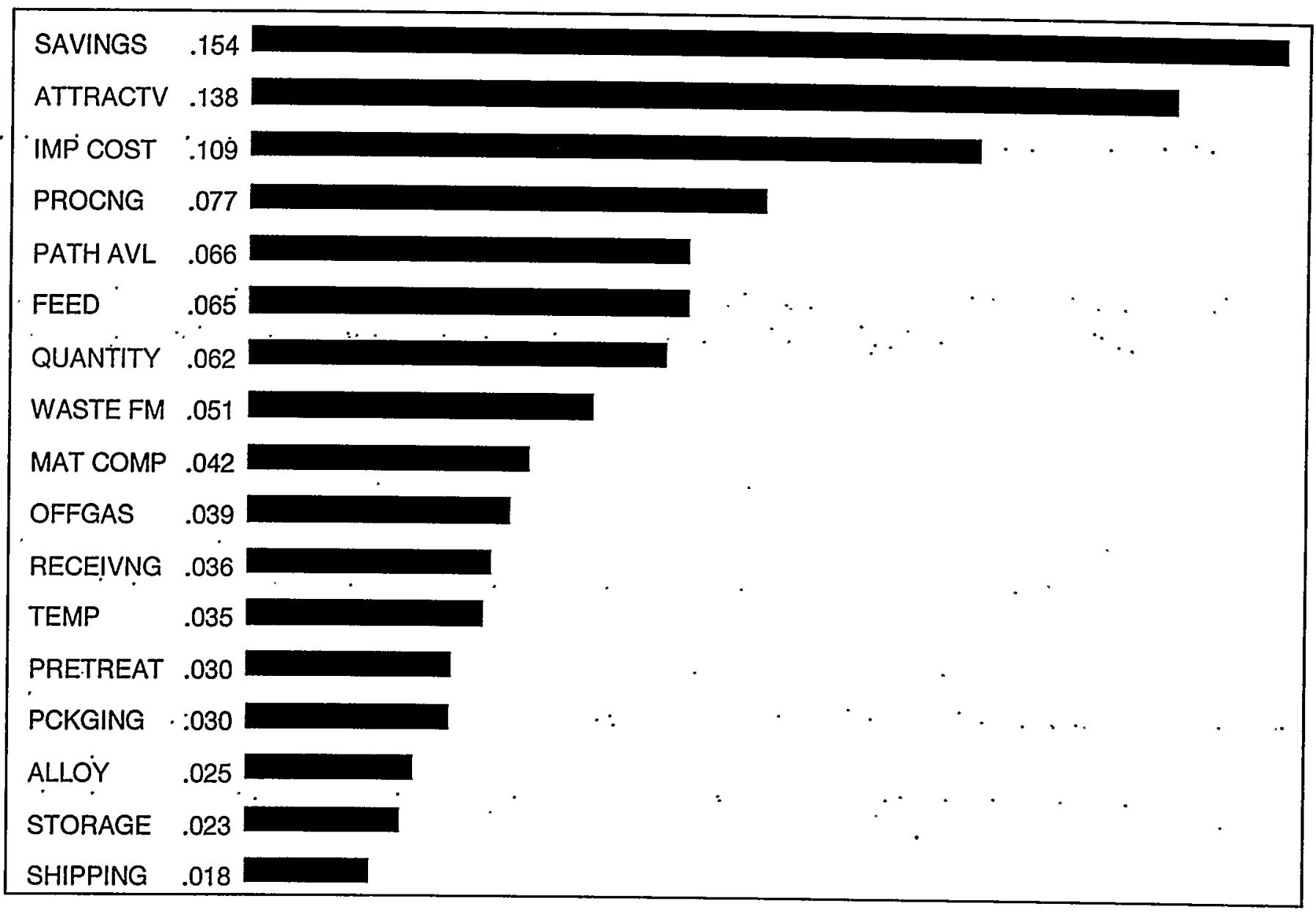

Figure 3. Relative Weights of Criteria 
Abbreviation

SAVINGS

ATTRACTV

IMP COST

PROCNG

PATTH AVL

FEED

QUANTITY

WASTE FM

MAT COMP

OFFGAS

RECEIVNG

TEMP

RECEIVNG

PATH AVL

PCKGING

ALLOY

WASTE FM

STORAGE

SHIPPING
Potential savings of using $M \& D$

Attractiveness of waste form; ease of certification

Cost to implement

Additional process $R \& D$ required.

Availability of current disposition path

Knowledge of feed composition

Quantity of material to be processed (months)

Additional waste form $R \& D$ required.

Compatibilities of materials with equipment

Offgas treatment required

Ability to receive material

Process Temperature required

Ability to receive material

Availability of current disposition path

Shipping prepations required.

Composition of final waste form (alloy?)

Additional waste form $R \& D$ required.

Material storage availability

Ability to ship out material

Table 2. Definitions for Criteria Abbreviations

\section{Materials To Be Evaluated}

This evaluation used primarily the three sources cited below to produce a list of potential candidate materials for screening, as summarized in Table 3. This materials list is not considered an exhaustive . list, as DOE has an ongoing Stewardship program that continues to refine site material holdings and the status of their disposition paths:

- In 1998, DOE/EM sponsored the Nuclear Materials Stewardship Program. This program examined the inventory of surplus materials across the Complex, and evaluated current and proposed disposition paths with respect to technical maturity, cost, schedule, and ES\&H variables. Nuclear material management plans were produced for plutonium and special transuranics (i.e., Np-237, Pu-238, Am-242, Pu-242), uranium (HEU, LEU, NU, DU, U-233), thorium, and sources, standards, and samples.

- In 1999, DOE also performed a canyon utilization study. This was in response to a concern expressed by the Defense Nuclear Facility Safety Board that the canyons not be shut down prematurely while materials needing their capabilities remained in DOE inventories. This study 
swept the Complex to identify materials that may need canyon processing for stabilization or recovery.

- Finally, the DOE National Spent Nuclear Fuel program maintains a list of irradiated fuel and targets remaining in inventory across the complex.

The broad categories of material examined thus include uranium (HEU, LEU, NU, DU, U-233), plutonium ( $\mathrm{Pu}-238, \mathrm{Pu}-239)$, higher transuranics (Am-241 samples and standards, $\mathrm{Am} / \mathrm{Cm}$ solutions,

- Am/Cm targets), and spent nuclear fuel.(11.types,including SS-clad oxides, $\mathrm{Zr}$-clad, metal fuels, graphite, etc.). 


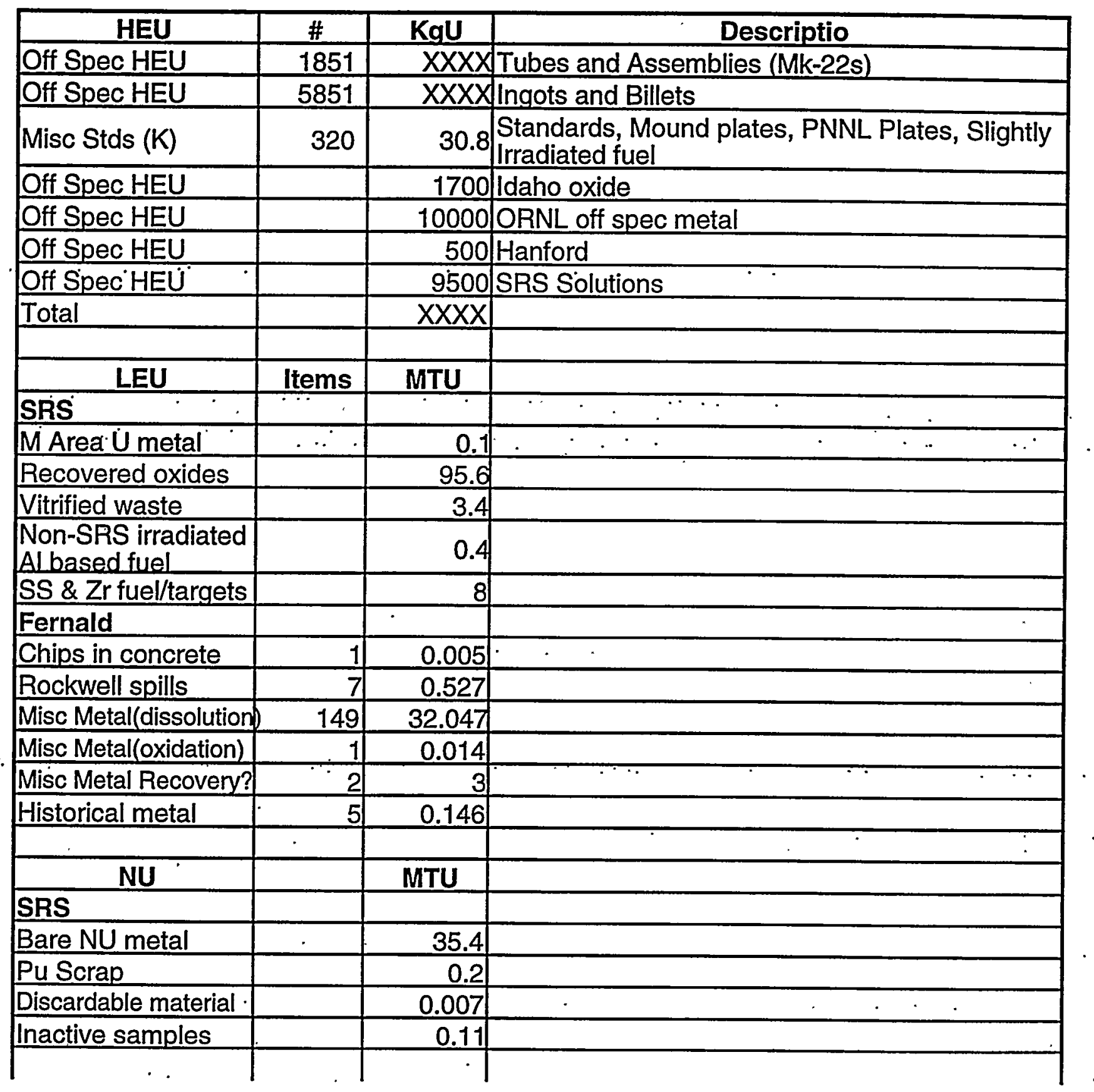

Table 3. Melt and Dilute Feed Candidates 


\begin{tabular}{|c|c|c|c|}
\hline DU & & MTU & \\
\hline \multicolumn{4}{|l|}{ SRS } \\
\hline DU/Al powder/castings & & 0.6 & \\
\hline Bare DU metal & & 938.2 & \\
\hline Canned DU metal & & 1652.5 & \\
\hline DU Solutions & & 236.9 & \\
\hline DU Oxides & & 19428.1 & \\
\hline Sludge \& filter cake & & 25.2 & \\
\hline Samples/stds & & 1.5 & \\
\hline EBR-II & & 16.7 & \\
\hline SS/Zr Fuel/targets & . & 0.1 & $\cdots$ \\
\hline Pu/DU oxide fuel rods & & 1.7 & \\
\hline Pu scrap & & 0.205 & \\
\hline Lab Solutions & & 0.005 & \\
\hline Discardable Material & & 0.001 & \\
\hline 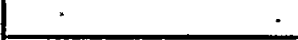 &. & $\dot{.}$ & $\cdot$ \\
\hline Fernald & Items & MTU & \\
\hline Chips in concrete & 1 & 0.009 & $\cdots$ \\
\hline Lead contaminated & 29 & 4.175 & \\
\hline Nonbumable metal & 1 & 0.042 & \\
\hline Rockwell spills & 17 & 3.063 & \\
\hline Misc Metal (dissolution) & 234 & 89.025 & \\
\hline Misc. Metal oxidation & 18 & 3.183 & \\
\hline Scrap U02 pellets & 23 & 2.186 & \\
\hline Historical Materials & 2 & 0.027 & \\
\hline. & & & - \\
\hline U-233 & Items & $\mathrm{Kg} \mathrm{U}-233$ & \\
\hline U-233 & 1505 & 790.7 & Total U is $1801 \mathrm{~kg}$ \\
\hline U-233/SNF & & 1106.1 & $\begin{array}{l}\text { Miscellaneous forms including carbide and MSRE } \\
\text { recovery material }\end{array}$ \\
\hline \multirow[t]{2}{*}{ Pu-238 scrap } & & & Various purities, lower than "fuel grade" for RTGs \\
\hline & & Kgs & \\
\hline \multirow[t]{2}{*}{ Np237 Scrap } & & 100 's & Currently as solution, planned to convert to oxide \\
\hline & $\#$ & Kgs & \\
\hline Pu-239 & Items & & \\
\hline Pits & \#\#\#\# & & \\
\hline Metal and Alloy & 4559 & & \\
\hline U/Pu/Zr Casting Scrap & 485 & & \\
\hline Mixed Oxide Slugs & 179 & & \\
\hline Oxide Powder & . :9707 & & 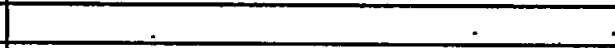 \\
\hline Pu/U oxide & 277 & & \\
\hline Pu scrap misc & 3341 & & \\
\hline ZPPR plates & 42412 & & Alloy \\
\hline Samples/Stds & 5 & & \\
\hline Combustibles & 2452 & & \\
\hline Misc. Compounds & 8999 & & \\
\hline Ash & 9171 & & $\dot{.}$ \\
\hline Chlorides, flourides etc & 7119 & & \\
\hline Pu/EU metal & 191 & & \\
\hline \multicolumn{4}{|l|}{ Am 241 samples/stds } \\
\hline Am 243 oxide & & & Currently tank 17.1 solution \\
\hline & & & \\
\hline Cm 244 solution & & & Currently tank 17.1 solution \\
\hline
\end{tabular}


Table 3. Melt and Dilute Feed Candidates (Continued)

\begin{tabular}{|c|c|c|c|}
\hline Mk 18s & & & Am/Cm/Pu-244 in aluminum \\
\hline Spent Fuel & MTU & Total Mass & \\
\hline Oxide-Commercial & & 165.5 & SST or Zr Clad LEU \\
\hline Oxide-Research & & 191.2 & SST/Zr Clad HEU/MEU, MOX \\
\hline Oxide, U/Th & & 124.6 & SST or Zr Clad HEU/MEU/LEU \\
\hline Oxide Disrupted TMI & & 331 & U Oxide failed or declad,, (LEU), TMI-2 \\
\hline Metal(U,U-Mo)/Na & & 120.4 & Na bonded SST clad, HEU/MEU/LEU/DU (fermi blankets) \\
\hline Metal U-Zr & & 0.1 & Zr Clad HEU/MEU/LEU/DU \\
\hline Al-clad U metal & & 3534 & LEU (SPR), EBRII \\
\hline Al Matrix & & 512.2 & U metal, oxide, silicide (19-93\%) \\
\hline Graphite & & 371 & U/Th carbide (HEU) \\
\hline Misc Other & & 33.9 & U-Zr-Hx, sST/IncoloyAl Clad HEU/MEU triga fuels \\
\hline Misc Other (failed) & & 12 & $\begin{array}{l}\text { U oxide failed.HEU/MEU. (SST/Zr), U carbide (non- } \\
\text { graphite), misc unknown }\end{array}$ \\
\hline Irradiated Reactor Parts & & & 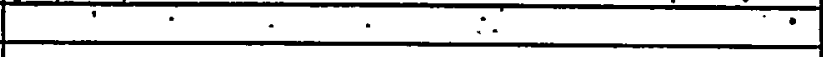 \\
\hline Irradiated Reactor Parts & & & \\
\hline
\end{tabular}

\section{Table 3. Melt and Dilute Feed Candidates (Continued)}

\section{Results Of Analysis}

With all criteria priorities and the ratings scheme defined by the team, materials were rated using the ECPro ${ }^{\text {TM }}$ program to derive an overall rating for each material. Summary results from this evaluation are summarized in Table 4. Details of the analysis are given in Appendix D for all the materials. It should be noted that some candidate materials were not evaluated as the team determined they were not suitable candidates (e.g., DU chips in concrete).

Materials in Table 4 seem to group into three natural groups. Those with the highest rating, highlighted in dark gray, have ratings between 0.65 and 0.86 . Since the rating of AI-matrix fuel slated for disposition in the melt-dilute facility is 0.752 , these materials appear to be good candidates for disposition through that facility.

The second group, highlighted in light gray, has ratings from 0.65 to 0.55 . These materials are less attractive but possible candidates. It may be that in doing process R\&D. for some of these materials, that some questions may be resolved that make them more attractive.

The first two groups include most of the plutonium materials currently scheduled for preparation for disposition in the new immobilization facility. Since this new facility represents a capital expenditure in excess of half a billion dollars, the use of melt and dilute for disposition of plutonium materials in lieu of immobilization deserves serious consideration. This kind of process also would make a homogeneous material meeting the original "Spent Fuel Standard" envisaged for plutonium disposition in the MGDS.

The third group, with a rating below 0.55 , is significantly less attractive than the two above. The three groups can be seen visually in Figure 4. 
Note that a number of uranium items scored highly in this rating. The melt-and-dilute process is essentially designed to use such material as an isotopic diluent for the A1/HEU spent fuel, and as expected would receive a high rating against the criteria used. For example scrap aluminum, if scored, would likewise be expected to receive a 'high' total score.

The ranking of score must then be tempered with the consideration of cost and 'risk' associated with continued storage of the material in its current form. For LEU/NU/DU metal or oxides, the materials are stable and have low associated health and safety concerns and minimal annual storage costs. DU -NU; and LEU are also often amenable to disposal as.low level waste (e.g., at the Nevada Test Site); Processing such materials in a melt-and-dilute facility in amounts beyond those needed for isotopic dilution of $\mathrm{HEU}$, although highly compatible, could actually increase the costs associated with disposition. A more detailed economic analysis of LEU/NU/DU items on a case-by-case basis would thus be required to determine costs of continued storage or processing for disposal as low level,waste in its current form, versus processing in the melt-and-dilute facility, storage, and . eventual permanent disposal. 


\begin{tabular}{|c|c|c|c|}
\hline Material & Total & Material & Total \\
\hline SRS DU discardable material & $38006857 \mathrm{a}$ & $\mathrm{Pu} / \mathrm{U}$ oxide & 0.6526 \\
\hline SRS DU Samples \& Standards & 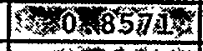 & $\mathrm{U}-233 / \mathrm{SNF}$ & 0.6469 \\
\hline $\mathrm{Pu} / \mathrm{EU}$ metal & $0 \times 8207$ & Cm 244 solution & 0.6457 \\
\hline SRS M Area U metal LEU & 0.8196 & Am 243 oxide & 0.6457 \\
\hline SRS Recovered oxides LEU & 07994 & Am 241. samples/stds & 0.6457 \\
\hline FMPC Misc DU metal (oxidation) & $06994 \times$ & Pu Mixed oxide slugs & 0.6442 \\
\hline Plates, HEU slightly irradiated & 0.7980 & Pu scrap misc & 0.6441 \\
\hline SRS DU lab solutions & 0.7967 & $\mathrm{Pu} \mathrm{Ash}$ & 0.6424 \\
\hline SRS DU Oxides & 0.7694 & ZPPR plates & 0.6288 \\
\hline Pu-238 scrap & 0.7690 & U/Pu/Zr Cásting Scráp & 0.6200 \\
\hline FMPC DU historical materials & 0.7674 & FMPC Rockwell spills LEU & 0.5915 \\
\hline SRS EBR-II (DU) & 0.7636 & $\begin{array}{l}\text { FMPC Misc LEU } \\
\text { Metal(dissolution) }\end{array}$ & 0.5915 \\
\hline Al-clad U metal SNF & 0.7636 & HEU SRS Solutions & 0.5812 \\
\hline \begin{tabular}{|l} 
SRS Bare DU metal \\
\end{tabular} & 0.9568 & SRS NU (PU) Scrap & 0.5742 \\
\hline SRS Canned DU metal $\quad \dot{\prime}^{\cdot}$ & 0.7568 & 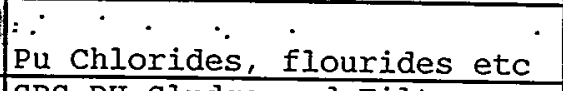 & $0.5658^{\circ}$ \\
\hline $\begin{array}{l}\text { HEU-Tubes and Assemblies (Mk- } \\
22 \mathrm{~s})\end{array}$ & 0.7549 & $\begin{array}{l}\text { SRS DU SIudge and Filter } \\
\text { Cake }\end{array}$ & 0.5653 \\
\hline Al Matrix SNE & 0,2472 & $\mathrm{Pu}$ Combustibles & 0.5517 \\
\hline FMPC Misc Metal(oxidation) LEU & 00 & SRS DU SS/Zr fuel/targets & 0.5394 \\
\hline Mk 18s. & 0.7398 & SRS PU/DU Oxide fuel rods & 0.5394 \\
\hline HEU ORNL off spec metal & 0.7337 & Np 237 scrap & 0.5167 \\
\hline SRS BARE NU Metal & 0.7319 & SRS Pu/DU scrap & 0.4890 \\
\hline SRS NU inactive samples & $0+7248$ & EMPC DU Nonburnable metal & 0.4706 \\
\hline U-233 (canned oxide) & $06242 \%$ & Pu-239 Pits & 0.4574 \\
\hline Metal and Alloy & $067236^{\circ}$ & FMPC DU lead contaminated & 0.4097 \\
\hline HEU Ingots. and Billets. . & 00,31807 & Metal U:Zr. SNF : & 0.3382 \\
\hline FMPC Scrap DU oxide pellets & 0.6762 & Metal $(\mathrm{U}, \mathrm{U}-\mathrm{MO}) / \mathrm{Na}$ SNF & 0.3382 \\
\hline SRS NU Discardable Material & 0.7134 & Oxide-Research SNF & 0.3103 \\
\hline SRS DU/AI powider castings & 0,7089 & Oxide-Commercial SNE & 0.3050 \\
\hline SRS DU Solutions & 0.7068 & Oxide Disrupted TMI SNF & 0.2705 \\
\hline Pu Misc. Compounds & $0 \% 7041$ & Oxide, U/Th SNF & 0.0000 \\
\hline HEU Idaho oxide & 0.6939 & FMPC Chips in concrete LEU & 0.0000 \\
\hline FMPC Misc Metal Recovery? LEU & 0.687 .6 & SRS Vitrified waste LEU & 0.0000 \\
\hline FMPC DU Rockwell spills & $.0 \% 6856 \%$ & FMPC DU chips in concrete & 0.0000 \\
\hline $\begin{array}{l}\text { FMPC Misc DU metal } \\
\text { (dissolution) }\end{array}$ & 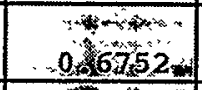 & Graphite SNF & 0.0000 \\
\hline Pu Oxide Powder & $0 \leq 6735$ & Misc Other SNE & 0.0000 \\
\hline Pu Samples/stds & 0.6708 & Misc Other (failed) & 0.0000 \\
\hline HEU Hanford & 0.6633 & Irradiated Reactor Parts & 0.0000 \\
\hline
\end{tabular}

NOTE: NR indicates Not Rated.

Table 4. Final Ratings Totals for Materials Evaluated 

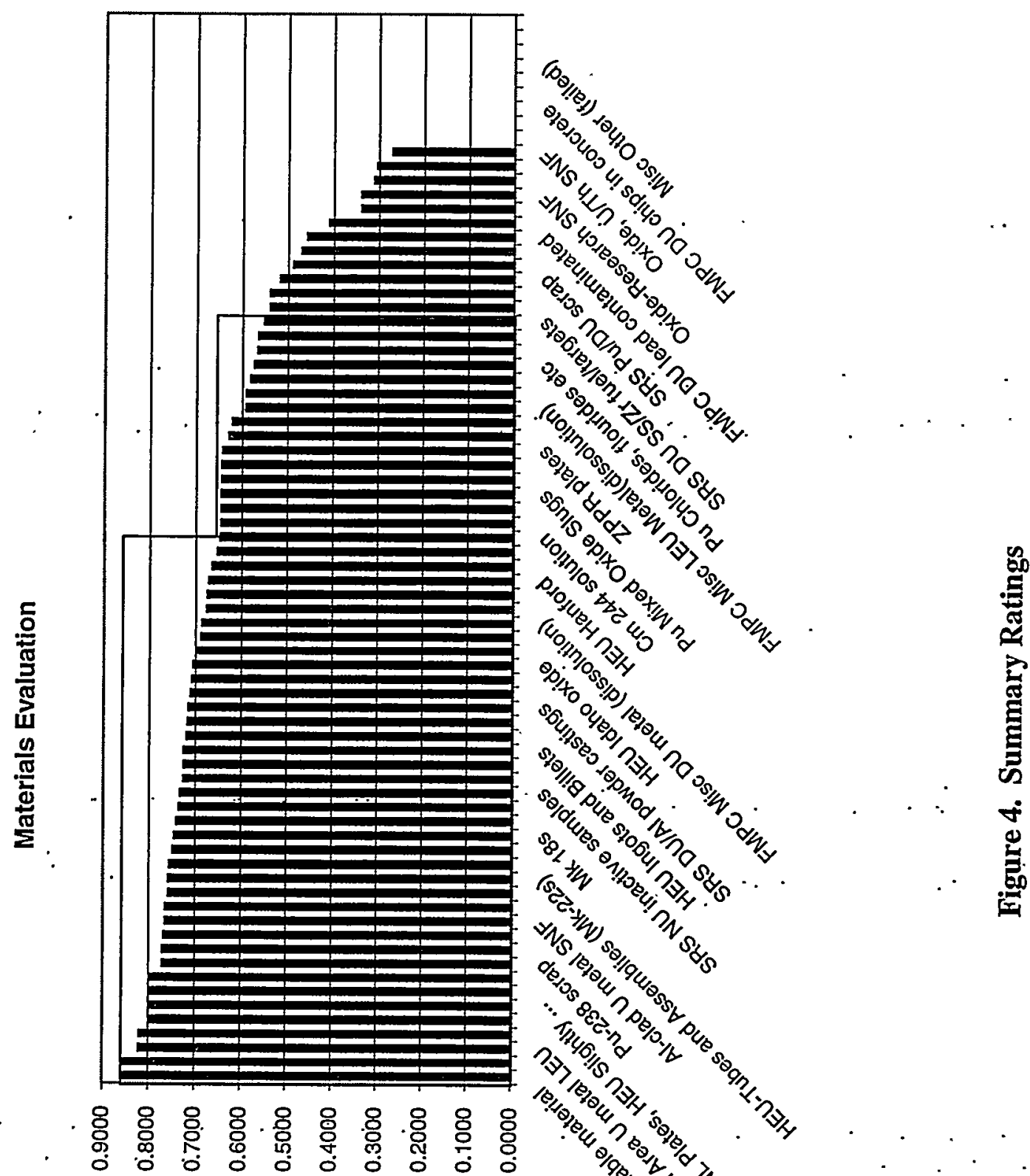

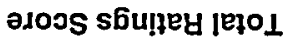

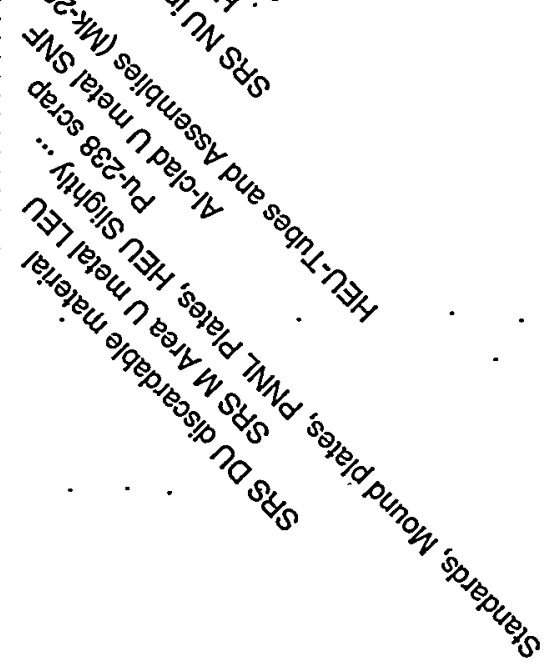





\section{CONCLUSIONS}

The melt and dilute facility represents an opportunity for disposition of a number of materials other than the Al matrix SNF for which it is intended. Although some materials on this list currently have planned dispositions, in a number of cases, melt and dilute represents a lower cost alternative.

This is especially true for miscellaneous plutonium materials currently slated for immobilization in a ceramic. Melt and dilute provides an alternative that, if combined with melt and dilute of Al-matrix fuel, could produce a waste form that would not require expensive new facilities (for immobilization and removal of cesium from SRS salt waste). This alternative would be at least as unattractive from a radiation and processing perspective as plutonium in commercial spent fuel.

Depleted uranium metal is the material of choice for operation of the melt and dilute facility, to be used for isotopic dilution of HEU in the U/Al spent fuel. As expected, DU metal and to a lessor degree oxides are highly compatible with the melt and dilute process and thus scored highly in this analysis due to high material compatibility. The same observation applies to NU and LEU.

However, the bulk of these materials as metal or oxides are stable and represent a very low risk and cost for continued storage. Also, DOE has not yet made a determination with regard to declaring inventories surplus to future use. If disposal becomes an option at some time in the future, packaging for disposal as low level waste (e.g., to the Nevada Test Site) has historically been a relatively low cost disposition path. As a results the economics of using a melt and dilute facility solely for

. .ptocessing LEU/NU/DU beyond that required for isotopic blend down of HEU in fuels. could not likely be justified. The relatively high scores assigned to such materials relative to the criteria used in this analysis must be tempered by this economic reality. .

Melt and dilute also provides a method for disposition of off-spec HEU materials should current negotiations with the Tennessee Valley Authority become unfruitful which would allow disposition of this material at $1 \%$ U-235 at moderate (operating only) cost.

It is also important to note that some materials.appear to be very. unattractive vis a vis the melt and dilute process. It is important that the Department of Energy follow through on development of. disposition paths for these materials.

\section{PATH FORWARD}

The following Phase II activities complete the requested assessment of the use of melt and dilute facility for the disposition of other materials:

1. Develop process flow sheets for each of the group one materials. Consider RCRA materials issues if applicable, waste streams and interim storage. 
2. Identify disposition paths for waste forms following M-D treatment, i.e., LLW, WIPP or MGDS and feasibility of obtaining waste form qualification.

3. Develop preliminary cost estimates and schedules.

4. Develop Monte Carlo risk analysis for implementation for recommended candidates.

5. Develop a final recommendation and path forward for recommended candidates in the form of a - final report.

A proposed schedule is shown below:



Figure 5. Proposed Phase II Schedule 


\section{REFERENCES}

1 G. Rudy to J. J. Buggy, letter, “ Path Forward on Alternative Technology”, dated September 7, 1999.

2 E. W. Zimmerman, Spent Nuclear Fuel Alternative Technology Decision Analysis, U-ESR-G-0004, Rev.0, June 28, 1998.

3

Dr. Thomas L. Saaty. Decision Making for Leaders. RWS Publications, Pittsburgh, PA 15213 (1995).

4 Faith Giglio. ECpro for Windows, Decision Support Software User Manual. Expert Choice, Inc., Pittsburgh, PA 15213 (1995). 


\section{APPENDICES}

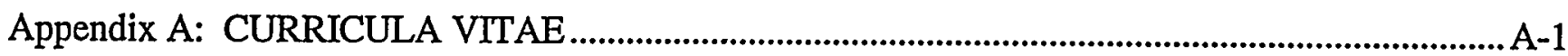

Appendix B: EVALUATIONS FOR CRITERIA IMPORTANCE................................................... B-1

Appendix C: RATINGS EVALUATIONS FOR MATERIALS ..................................................... C-1

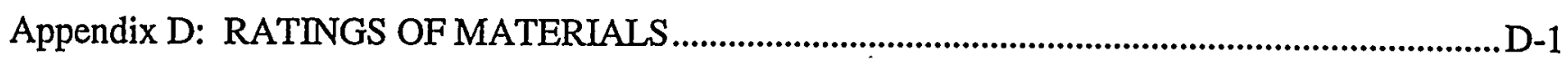


APPENDIX A

CURRICULA VITAE 
This page intentionally left blank 


\section{Harold B. Peacock, Jr., Ph.D.}

Harold Peacock holds a B.S. degree in Mechanical Engineering and a M.S. degree in Metallurgy from the Georgia Institute of Technology. He received a Ph.D. degree in Metallurgical Engineering from the University of Tennessee. He has 30 years experience in R\&D in the area of technology development.

Dr. Peacock is an Advisory Engineer at the Savannah River Technology Center and has published over 75 papers in journals and conference proceedings. He holds one U.S. patent in solid state welding. He developed a powder metallurgical process for blending and isostaticly compacting powders for extrusion billet cores as well as methods for extrusion of SRS reactor fuel tubes. He was principal investigator in the development of (1) long-term corrosion testing of aluminum alloys at high temperature and humidity conditions, (2) solid state welding of depleted uranium slugs for plutonium production, and (3) design and fabrication of targets for the accelerator production of tritium at Los Alamos. He is currently responsible for the development of the melt-dilute technology for treatment of aluminum-base research reactor spent nuclear fuel.

He is a member of the ASM International (ASM) and the Society of Engineering Mechanics (SEM), and has served as program Chairman for the ASM Society's Savannah River local chapter. He has taught mechanical and metallurgical engineering courses at Universities for the past 15 years.

\section{Thad Adams, Ph.D.}

Dr. Thad Adams received his M.S. (1994) and Ph.D. (1997) from the University of Florida in Materials Science and Engineering. Prior to this, his B.S degree (1991) was earned from the University of Tennessee. His studies have concentrated on the liquid metal corrosion/embrittlement, advance nuclear fuel development, phase transformations and microstructural evolution in advanced materials. Additionally, Dr. Adams has worked in the areas of materials processing, metallic glasses, thin.films, and temperature gradient zone melting. He has also performed fundamental thermodynamic modeling of advanced materials system with respect to phase formation and binary and ternary equilibrium and metastable phase diagrams. Dr. Adams has extensive knowledge of materials characterization techniques including SEM, EDAX/WDAX, TEM, XRD, Hi-Temp XRD, DSC, DTA, TGA. Dr. Adams has given numerous technical presentations and has published 10 technical papers in journals and conference proceedings. For the past two years, he has held the position of senior engineer at WSRC, where he leads the development effort for spent nuclear fuel alternative disposal technology (SNFADT).

\section{Helen Brooks}

Ms. Brooks received a B.S. degree in Chemical Engineering from Tennessee Technological University and a Masters in Environmental Engineering from Auburn University. She has 11 years experience at Savannah River Site primarily associated with nuclear production reactor operations and spent nuclear fuel receipt engineering. Ms. Brooks has held positions in reactor operations supervision and management, heavy water operations, and fuel receipt engineering. In her current assignment, Ms. Brooks is responsible for the management of the Alternate Technology Program that includes validation of the melt-dilute technology and qualification of the waste form for the repository. 


\section{Joseph F. Krupa}

M.E. Ch. E. University of Idaho

M.Sc. in Chemistry, University of California Berkeley -- (AEC fellowship in Nuclear Science and Engineering B.Sc. in Chemistry, U.S. Air Force Academy, CO

Mr. Krupa has over 26 years experience in the nuclear field. He started his career performing radiochemical analyses as a Nuclear Research Officer in the U.S. Air Force. He then spent 10 years at the Idaho Chemical Processing Plant performing studies of actinide removal from spent fuel waste using bidentate phosphorous ligands. He was the lead for a NRC funded experimental program to evaluate post-accident (nuclear) radio-iodine sampling and measurement equipment.

He developed Flourinel Dissolution Process reagent addition computer programs for which he was awarded George Westinghouse bronze award in 1985. He was a key player in the successful modification and implementation of the Fluorinel Process for Naval Fuel dissolution including developing analytical methods for process control, modeling of process dissolution criticality permitting deletion of a major system, operating the Fluorinel Dissolution Pilot Plant and acting as a startup engineer for the Fluorinel Dissolution hot startup.

From 1987-1992, he was a Nuclear Engineer for the Department of Energy's Savannah River Operations Office. During his tenure, he acted as DOE Nuclear Materials Manager; coordinated and reviewed technical planning studies on nuclear materials disposition, transportation and capital asset management, and participated in task forces on capital asset management, reconfiguration siting, and plutonium . discard limits.

Mr. Krupa has, as a Principal Technical Advisor for Westinghouse Savannah River Company, published two studies of Al-clad spent fuel options to support Department of Energy Environmental Impact Statement Records of Decision. The latest study also provides cost and schedule information for a study of the non-proliferation impacts of spent fuel reprocessing. He has co-authored studies of life-cycle costs for spent fuel disposition with criticality prevention, SRS spent fuel storage, SRS plutonium discard limit implementation, SRS nuclear materials disposition and complex-wide nuclear material disposition issues.

He is active in the American Chemical Society (30 years) and American Nuclear Society, and has served as the Chairman of the American Chemical Society's Savannah River Local Section. He is also a member of the International Council of Systems Engineers (INCOSE) and the American Society for Engineering Management. 


\section{William F. Swift}

Mr. Swift received his B.S. in Chemical Engineering from the University of Notre Dame. He has 18 years experience at Savannah River Site primarily associated with nuclear production reactor engineering. Mr. Swift has held engineering assignments in day-to-day operations, reactor components support, long-range planning and capital project development. He has also held engineering management assignments in systems engineering, as the engineering representative to the joint test group and for development of capital projects. Mr. Swift has also held positions as manager of solid waste engineering support and as manager of the site geotechnical groundwater modeling group. In his current assignment, Mr. Swift is responsible for supporting development of alternative technologies for disposition of spent nuclear fuel and development of a project to implement the chosen technology.

\section{Wade E. Bickford}

Wade Bickford is a Senior Consulting Engineer working for Westinghouse in the Strategic Planning and Integration Department at the Savannah River Site. He has over 25 years experience in nuclear design and safety in the DOE complex. At the Pacific Northwest National Laboratory at Hanford, Mr. Bickford rose to the position of Senior Scientist in fusion research, and later transitioned to nuclear reactor safety, and advanced nuclear concepts development. In 1988, Mr. Bickford accepted a position in the Reactor Physics group at the Savannah River Site for work on a new production reactor. During this period, he was the site representative to national technical working groups on facility design and thermal hydraulics, as well as task manager and technical contributor for reactor safety analysis and engineering studies to support environmental documentation. This diverse background led to a position in site planning in 1992, where he has supported site and national planning efforts for transition of DOE to post-Cold War missions. Wade Bickford received his undergraduate degree in Mathematics from Washington State University, and was elected to the Phi Beta Kappa honorary:" He received his M.S. degree in Nuclear Engineering from the University of Washington. He is also a licensed Professional Engineer (Mechanical). 
This page intentionally left blank 
APPENDIX B

CRITERIA EVALUATION 
The table below indicates the raw scores and geometric means for the model criteria.

\begin{tabular}{|l|l|r|r|r|r|r|r|r|r|}
\cline { 3 - 8 } \multicolumn{2}{c|}{} & Adams & Krupa & Bickford & Peacock & Swift & Brooks & G.M. & 1/G.M. \\
\hline Disposition Compatibitility & Process & 5.000 & 0.333 & 0.167 & 7.000 & 6.000 & 4.000 & 1.897 & \\
\hline Economic Advantage & Process & 0.500 & 0.250 & 0.143 & 1.000 & 0.500 & 0.333 & 0.379 & 2.637 \\
\hline Transportation & Process & 4.000 & 3.000 & 5.000 & 5.000 & 3.000 & 1.000 & 3.107 & \\
\hline Tech Development & Process & 1.000 & 4.000 & 1.000 & 5.000 & 1.000 & 0.250 & 1.308 & \\
\hline Economic Advantage & Disposition Compatibitility & 3.000 & 0.333 & 4.000 & 2.000 & 0.200 & 0.200 & 0.827 & 1.209 \\
\hline Transportation & Disposition Compatibitility & 5.000 & 3.000 & 6.000 & 5.000 & 1.000 & 0.500 & 2.466 & \\
\hline Tech Development & Disposition Compatibitility & 2.000 & 3.000 & 5.000 & 1.000 & 0.500 & 1.000 & 1.570 & \\
\hline Transportation & Economic Advantage & 5.000 & 5.000 & 3.000 & 0.250 & 3.000 & 3.000 & 2.351 & \\
\hline Tech Development & Economic Advantage & 1.000 & 4.000 & 3.000 & 4.000 & 2.000 & 1.000 & 2.140 & \\
\hline Tech Development & Transportation & 5.000 & 1.000 & 1.000 & 1.000 & 1.000 & 1.000 & 1.308 & \\
\hline
\end{tabular}

\begin{tabular}{|c|c|c|c|c|c|c|c|c|c|}
\hline Offgas & Temperature & 0.333 & 3.000 & 0.333 & 8.000 & 2.000 & 0.250 & 1.049 & \\
\hline Alloy composition & Temperature & 1.000 & 3.000 & 0.333 & 9.000 & 2.000 & 1.000 & 1.619 & \\
\hline Feed Knowledge & Temperature & 0.333 & 3.000 & 0.200 & 0.200 & 0.250 & 0.167 & 0.344 & 2.904 \\
\hline Material Compatibility & Temperature & 1.000 & 1.000 & 0.200 & 6.000 & 0.500 & 0.333 & 0.765 & 1.308 \\
\hline Pretreatment requirements & Temperature & 0.333 & 5.000 & 0.333 & 6.000 & 0.500 & 11.000 & 1.624 & \\
\hline Alloy composition & Offgas & 5.000 & 3.000 & 2.000 & 0.167 & 2.000 & 6.000 & 1.979 & \\
\hline Feed Knowledge & Offgas & 3.000 & 3.000 & 0.250 & 0.143 & 0.250 & 1.000 & 0.657 & 1.522 \\
\hline Material Compatibility & Offgas & 3.000 & 1.000 & 0.250 & 0.200 & 1.000 & 0.500 & 0.649 & 1.540 \\
\hline Pretreatment requirements & Offgas & 3.000 & 5.000 & 0.250 & 6.000 & 1.000 & 0.500 & 1.497 & \\
\hline Feed Knowledge & Alloy Composition & 0.333 & 0.500 & 0.250 & 1.000 & 0.250 & 4.000 & 0.589 & 1.698 \\
\hline Material Compatibility & Alloy Composition & 1.000 & 0.500 & 0.200 & 4.000 & 0.500 & 0.200 & 0.585 & 1.710 \\
\hline Pretreatment requirements & Alloy Composition & 0.333 & 3.000 & 0.200 & 5.000 & 0.500 & 0.500 & $\overline{0.794}$ & 1.260 \\
\hline Material Compatibility & Feed Knowledge & 3.000 & 1.000 & 0.200 & 6.000 & 3.000 & 1.000 & 1.487 & \\
\hline Pretreatment requirements & Feed Knowledge & 4.000 & 3.000 & 2.000 & 1.000 & 3.000 & 3.000 & 2.449 & \\
\hline Material Compatibility & Pretreatment requirements & 0.333 & 1.000 & 1.000 & 1.000 & 1.000 & 1.000 & 0.833 & 1.201 \\
\hline
\end{tabular}

\begin{tabular}{|c|c|c|c|c|c|c|c|c|c|}
\hline & & Adams & Krupa & Bickford & Peacock & Swift & Brooks & G.M. & $\overline{1 / G I}$ \\
\hline Attractiveness of Waste Fm & Availability of current path & 0.333 & 0.333 & 1.000 & 0.200 & 0.200 & 3.000 & 0.487 & 2.054 \\
\hline Potential Cost Savings & Cost to Implement & 1.000 & 0.333 & 0.167 & 1.000 & 1.000 & 4.000 & 0.778 & 1.28 \\
\hline Quantity of Material & Cost to Implement & 3.000 & 4.000 & 7.000 & 0.333 & 1.000 & 0.500 & 1.552 & \\
\hline Quantity of Material & Potential Cost Savings & 3.000 & 5.000 & 7.000 & 7.000 & 1.000 & 0.500 & 2.676 & \\
\hline Shipping & Theceiving & 4.000 & 1.000 & 4.000 & 5.000 & 1.000 & 4.000 & 2.615 & \\
\hline Packaging & Receiving & 4.000 & 0.333 & 1.000 & 0.200 & 1.000 & 4.000 & 1.011 & 0.989 \\
\hline Storage & Receiving & 4.000 & 2.000 & 0.333 & 1.000 & 1.000 & 3.000 & 1.414 & \\
\hline Packaging & Shipping & 1.000 & 0.333 & 0.333 & 4.000 & 1.000 & 0.500 & 0.778 & 1.285 \\
\hline Storage & Shipping & 0.333 & 1.000 & 0.333 & 5.000 & 1.000 & 0.500 & 0.808 & 1.238 \\
\hline Storage & Packaging & 1.000 & 4.000 & 0.333 & 6.000 & 1.000 & 1.000 & 1.414 & \\
\hline Processing & Waste Form & 1.000 & 2.000 & 5.000 & 4.000 & 1.000 & 0.333 & 1.540 & \\
\hline
\end{tabular}




\section{Develop a ratings for attractiveness for using melt and dilute}

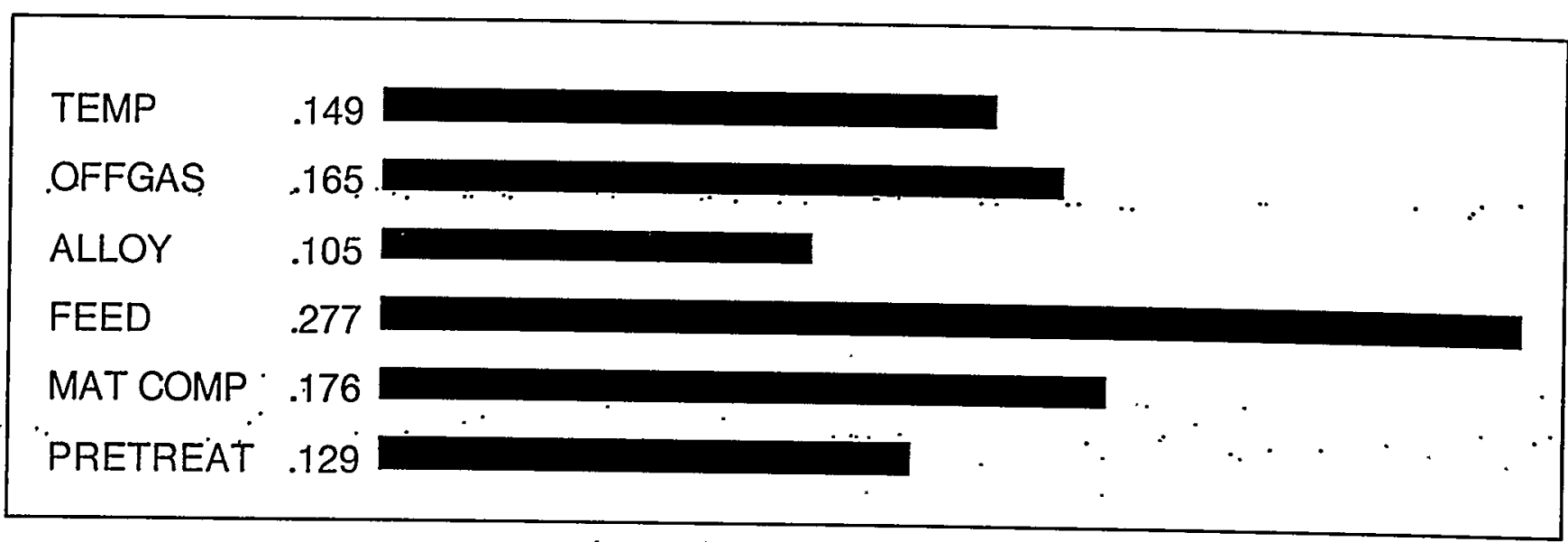

Inconsistency Ratio $=0.03$

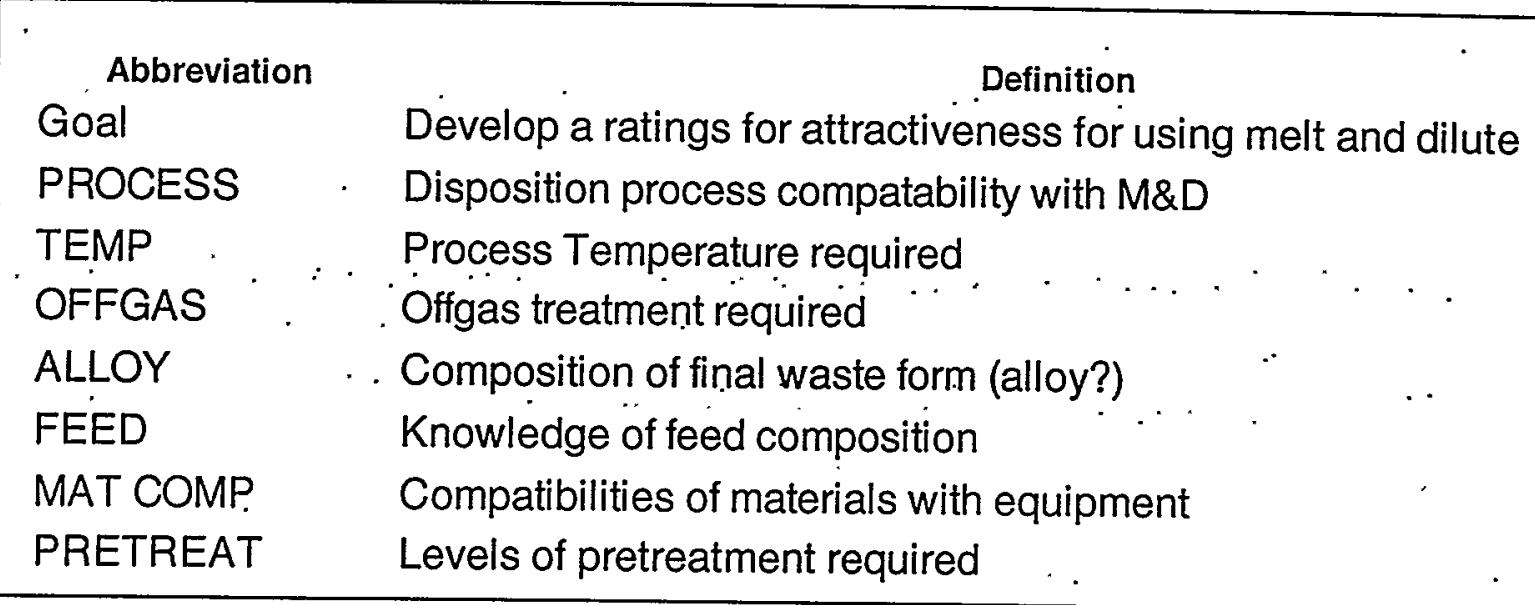




\section{Develop a ratings for attractiveness for using melt and dilute}

PATH AVL .323

ATTRACTV .677

Inconsistency Ratio $=0.0$

Abbreviation

Goal $\cdots$. . Develop a ratings for attractiveriess for using melf and dilute DISPOSIT $\therefore$ Compatability of waste form with Yucca; WIPP; LLW etc.

PATH AVL 'Availability of current disposition path

ATTRACTV Attractiveness of waste form; ease of certification

\section{Develop a ratings for attractiveness for using melt and dilute}

\section{IMP COST $: 334$ \\ SAVINGS $\quad .474$ \\ QUANTITY .192}

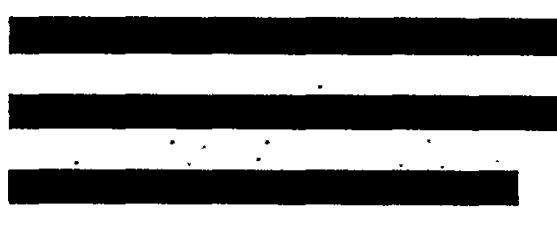

Inconsistency Ratio $=0.01$

Abbreviation

Goal

ECON.AD

IMP COST

SAVINGS

QUANTITY

\section{Definition}

Develop a ratings for attractiveness for using melt and dilute

Potential for savings

Cost to implement

Potential savings of using M\&D

Quantity of material to be processed (months) 


\section{Develop a ratings for attractiveness for using melt and dilute}

\section{RECEIVNG .336 \\ SHIPPING $\quad .171$ \\ .PCKGING. .281 . \\ STORAGE $\quad .212$}

Inconsistency Ratio $=0.02$

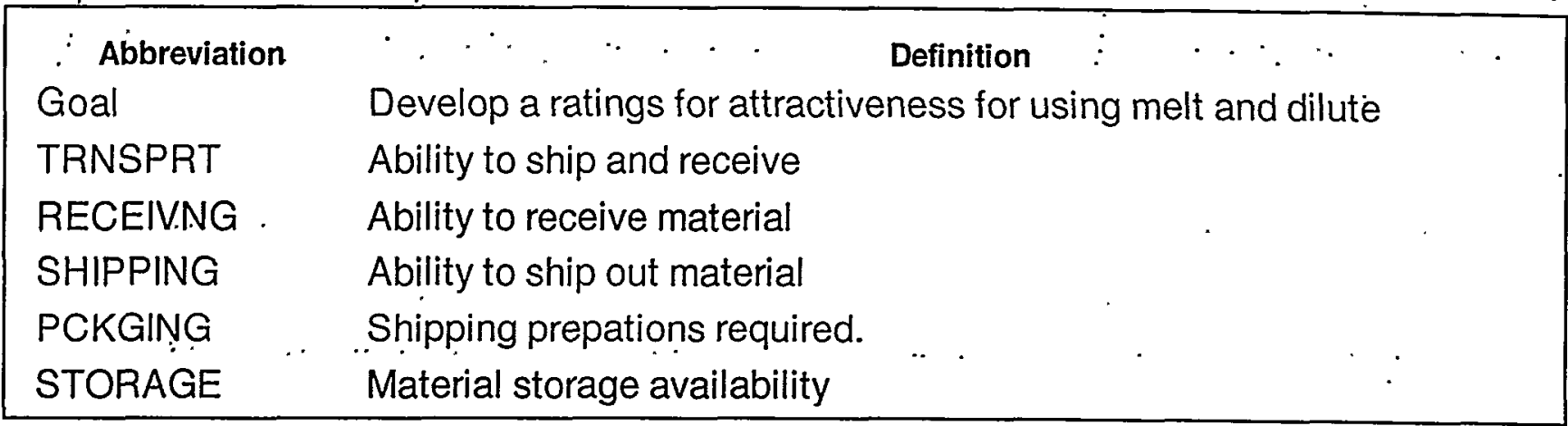

\section{Develop a ratings for attractiveness for using melt and dilute}

Inconsistency Ratio $=0.0$

PROCNG $\quad .600$

WASTE FM $\quad .400$

Abbreviation

Goal

TECH DEV

PROCNG

WASTE FM

\section{Definition}

Develop a ratings for attractiveness for using melt and dilute Technology Development Required Additional process $R \& D$ required. Additional waste form $R \& D$ required. 


\section{APPENDIX C}

\section{RATINGS EVALUATIONS FOR MATERIALS}


Scale pair-wise comparisons are given by evaluator in the table below.

\begin{tabular}{|c|c|c|c|c|c|c|c|c|}
\hline Evaluator & Adams & Peacock & Swift & Bickford & Brooks & Krupa & GM & $1 / G M$ \\
\hline \multicolumn{9}{|l|}{ Temp } \\
\hline 850 vs 1200 & 0.25 & .166667 & 0.2 & 0.166667 & $\overline{0.25}$ & 0.2 & 0.20274 & 4.932424 \\
\hline 850 vs 1400 & 0.142857 & 0.142857 & 0.142857 & 0.142857 & 0.166667 & 0.142857 & 0.146575 & 6.822448 \\
\hline 850 vs $>1400$ & 0.1111111 & 0.111111 & 0.111111 & 0.125 & 0.125 & $\overline{0.111111}$ & 0.11556 & 8.653497 \\
\hline 1200 vs 1400 & 0.333333 & 0.2 & 0.333333 & 0.166667 & 0.333333 & $\overline{0.2}$ & 0.250471 & 3.992478 \\
\hline $1200 v s \cdot>1400$ & 0.2 & 0.125 & 0.2 & 0.142857 & 0.2 & 0.142857 & 0.165311 & 6.04922 \\
\hline 1400 vs $>1400$ & 1 & 0.2 & 0.333333 & 0.166667 & 0.5 & 0.2 & 0.32183 & 3.107233 \\
\hline \multicolumn{9}{|l|}{ Offgas } \\
\hline No-P vs ONEHEPA & 0.333333 & 0.25 & 0.5 & 0.25 & 0.25 & $\overline{0.2}$ & 0.28365 & 3.525469 \\
\hline No-P vs M\&DSYS & 0.25 & 0.2 & 0.5 & 0.2 & 0.2 & 0.142857 & 0.228639 & 4.373707 \\
\hline No-P vs SAND & 0.142857 & 0.25 & .0 .25 & 0.166667 & 0.125 & 0.111111 & 0.16566 & 6.036478 \\
\hline ONEHEPA vS M\&DSYS & 0.5 & 0.333333 & 0.5 & 0.25 & 0.5 & 0.333333 & 0.389136 & 2.569797 \\
\hline QNEHEPA VS'SAND & 0.142857 & 0.2 & 0.25 & 0.2 & 0.2 & 0.166667 & 0.190384 & 5.252546 \\
\hline M\&DSYS vs SAND & 0.333333 & 0.333333 & 0.2 & 0.25 & 0.333333 & 0.25 & 0.278136 & $3: 595359$ \\
\hline \multicolumn{9}{|l|}{ Alloy } \\
\hline Compat vs Marg Dep & 1 & 0.5 & 0.25 & 0.25 & 0.5 & 0.333333 & 0.416342 & 2.401874 \\
\hline Compat vs Sig Dep & 0.5 & 0.25 & 0.142857 & 0.2 & 0.2 & 0.2 & 0.228639 & 4.373707 \\
\hline Compat vs New Mat & 0.2 & 0.166667 & 0.333333 & 0.166667 & 0.142857 & 0.142857 & 0.18319 & 5.458814 \\
\hline Marg Dep vs Sig Dep & 0.5 & 0.5 & 0.166667 & 0.25 & 0.333333 & 0.333333 & 0.324027 & 3.086164 \\
\hline Marg Dep vs New Mat & 0.2 & 0.333333 & 0.166667 & 0.2 & 0.142857 & 0.2 & 0.199735 & 5.006645 \\
\hline Sig Dep v.s New Mat & 0.2 & & 0.5 & 0.25 & 0.25 & 0.333333 & 0.357377 & 2.798166 \\
\hline \multicolumn{9}{|l|}{ Feed } \\
\hline WELLCHAR vs. Proc. Kno & 1 & 0.333333 & 0.333333 & 0.25 & 0.333333 & 0.333333 & 0.381571 & 2.620741 \\
\hline WELLCHAR vs. Mat Des & 0.25 & 0.2 & 0.2 & 0.2 & 0.25 & 0.2 & 0.215443 & 4.641589 \\
\hline WELLCHAR VS UK & 0.142857 & 0.166667 & 0.142857 & 0.166667 & 0.142857 & 0.125 & 0.14708 & 6.799043 \\
\hline Proc Kno vs. Mat Des. & 0.333333 & 0.25 & 0.333333 & 0.333333 & 0.5 & 0.25 & .0 .324027 & 3.086164 \\
\hline Proc Kno vs. UK & 0.142857 & 0.25 & 0.2 & 0.25 & 0.2 & 0.142857 & 0.192586 & 5.192494 \\
\hline Mat Des vs. UK & 0.2 & 0.166667 & 0.333333 & 0.333333 & 0.25 & 0.333333 & 0.259962 & 3.846722 \\
\hline \multicolumn{9}{|l|}{ Mat Comp. } \\
\hline Current vs Graphite & & 0.333333 & 0.5 & 0.142857 & 0.333333 & 0.333333 & 0.371893 & 2.688945 \\
\hline vs. Nitride & 0.333333 & 0.25 & 0.25 & 0.125 & 0.166667 & $\overline{0.2}$ & 0.210422 & 4.752354 \\
\hline Graphite vs. Nitride & 0.333333 & 0.2 & 0.333333 & 0.142857 & 0.25 & 0.333333 & 0.253368 & 3.946832 \\
\hline \multicolumn{9}{|l|}{ Pretreat } \\
\hline No-P vs Min-P & 1 & 0.333333 & 0.333333 & 0.25 & 0.5 & 0.333333 & 0.408248 & 2.44949 \\
\hline No-P vs Sig-P & 0.25 & 0.25 & 0.166667 & 0.2 & 0.25 & 0.166667 & 0.210422 & 4.752354 \\
\hline Min-P vs Sig-P & 0.5 & 0.2 & 0.333333 & 0.25 & 0.333333 & 0.25 & 0.297582 & 3.360421 \\
\hline
\end{tabular}




\begin{tabular}{|c|c|c|c|c|c|c|c|c|}
\hline Evaluator & Adams & Peacock & Swift & Bickford & Brooks & Krupa & GM & $1 / \mathrm{GM}$ \\
\hline \multicolumn{9}{|l|}{ Path Avl } \\
\hline Defined vs. Avallable & 1 & 5 & 2 & 4 & $\mathbf{T}$ & 4 & 2.329986 & \\
\hline Defined vs. Proposed & 3 & 6 & 3 & 5 & 2 & 6 & 3.846722 & \\
\hline Defined vs Undef & 5 & 7 & 4 & $\overline{6}$ & 4 & 8 & 5.473161 & \\
\hline Available vs Proposed & 4 & 3 & 2 & 5 & 2 & 4 & 3.140836 & \\
\hline Avallable vs. Undef & 5 & 4 & 3 & $\overline{6}$ & 4 & 6 & 4.529869 & \\
\hline Proposed vs. Undef & 5 & 4 & 2 & 5 & 3 & 4 & 3.659052 & \\
\hline \multicolumn{9}{|l|}{ Attractiv } \\
\hline Similar vs. Sim-Mod & 1. & 0.25 & 0.5 & 0.25 & 1 & 0.333333 & 0.467328 & 2.139826 \\
\hline Similar vs. Sig Eff & 0.2 & 0.2 & 0.2 & 0.333333 & 0.25 & 0.142857 & 0.213699 & 4.679487 \\
\hline Sim-Mod vs Sig Eff & 0.2 & $\therefore$ & 0.25 & 0.25 & 0.2 & $\cdot 0.2$ & 0.215443 & 4.641589 \\
\hline \multicolumn{9}{|l|}{ Imp Cost } \\
\hline Opsonly vs MinorCap & 0.5 & 0.5 & 0.5 & 0.166667 & 1 & 0.333333 & 0.43679 & 2.289428 \\
\hline Opsonly vs SigCap & 0.25 & 0.333333 & 0.25 & 0.2 & 0.333333 & 0.2 & 0.255436 & 3.914868 \\
\hline Opsonly vs MajCap & 0.142857 & 0.333333 & 0.166667 & 0.25 & 0.166667 & 0.111111 & 0.182332 & 5.484504 \\
\hline MinorCap vs SigCap & 0.333333 & 0.5 & 0.333333 & 0.2 & 0.333333 & 0.25 & 0.312197 & 3.203101 \\
\hline MinorCap vs MajCap & 0.2 & 0.25 & 0.2 & 0.25 & 0.2 & 0.166667 & 0.208995 & 4.784797 \\
\hline SigCap vs MajCap & 0.333333 & 0.5 & 0.25 & 0.25 & 0.25 & 0.25 & 0.294398 & 3.396763 \\
\hline \multicolumn{9}{|l|}{ Savings } \\
\hline MINRSAV VS MODSAV & 1 & 2 & 3 & 7 & 2 & 2 & 2.34901 & \\
\hline MINRSAV vs SIGSAV & 4 & 3 & 4 & 8 & 4 & 4 & 4.279653 & \\
\hline MINRSAV vS MAJSAV & 7 & 4 & 6 & 9 & 6 & 6 & 6.156148 & \\
\hline MINRSAV VS MAXSAV & 9 & 4 & 8 & 9 & 8 & 9 & 7.559526 & \\
\hline MODSAV VS SIGSAV & 3 & 2 & 3 & 7 & 3 & 2 & 3.018239 & \\
\hline MODSAV vs MAJSAV & 5 & 3 & 5 & 8 & 5 & 5 & 4.966097 & \\
\hline MODSAV VS MAXSAV & 9 & 4 & 7 & 9 & 7 & 8 & 7.089874 & \\
\hline SIGSAV VS MAJSAV & 3 & 2 & 3 & 8 & 3 & 4 & 3.464102 & \\
\hline SIGSAV.VS MAXSAV & 5 & 3 & 5 & 9 & 6 & 6 & 5.381885 & \\
\hline MAJSAV vs MAXSAV & 6 & 2 & 2 & 8 & 6 & 5) & 4.233866 & \\
\hline \multicolumn{9}{|l|}{ Quantity } \\
\hline INSIG VS MINOR & 1 & 0.5 & 0.333333 & 0.2 & 1 & 0.333333 & 0.472382 & 2.116933 \\
\hline INSIG vS MODERATE & 3 & 0.333333 & 0.2 & 0.166667 & 2 & 0.2 & 0.486956 & 2.053573 \\
\hline INSIG vS SIGNIF & 3 & 0.25 & 0.142857 & 0.142857 & 3 & 0.166667 & 0.443921 & 2.252652 \\
\hline MINOR VS MODERATE & 1 & 0.5 & 0.5 & 0.166667 & 11 & 0.5 & 0.524558 & $1: 906369$ \\
\hline MINOR vs SIGNIF & 3 & 0.333333 & 0.25 & 0.142857 & 2 & 0.25 & 0.511252 & 1.955981 \\
\hline MODERATE vs SIGNIF & 0.333333 & 0.5 & 0.5 & 0.166667 & 2 & 0.333333 & 0.458243 & 2.182247 \\
\hline \multicolumn{9}{|l|}{ RECEIVNG } \\
\hline Cur. REC. vs REC MOD & 0.333333 & 0.333333 & 0.5 & 0.25 & 0.25 & 0.25 & 0.308857 & 3.237741 \\
\hline CUR REC VS NOREC & 0.2 & 0.2 & 0.25 & 0.2 & 0.166667 & 0.142857 & 0.190384 & 5.252546 \\
\hline AECMOD VS NOREC & 0.333333 & 0.25 & 0.333333 & 0.25 & 0.333333 & 0.2 & 0.278136 & 3.595359 \\
\hline \multicolumn{9}{|l|}{ SHIPPING } \\
\hline SHIPCUR VS SHIP.INC & $0: 333333$ & .0 .5 & 0.333333 & 0.25 & 0.333333 & 0.333333 & 0.339941 & 2.941683 \\
\hline SHIPCUR vs SHIP.UN & 0.2 & 0.25 & 0.2 & 0.2 & 0.2 & 0.2 & 0.207578 & 4.817462 \\
\hline SHIP.INC vs SHIP.UN & 0.333333 & 0.5 & 0.333333 & 0.25 & 1 & 0.333333 & 0.408248 & 2.44949 \\
\hline \multicolumn{9}{|l|}{ PCKGING } \\
\hline PACKAGED vS PACKK REQ & 0.333333 & 0.5 & 0.333333 & 0.333333 & 0.5 & 0.5 & 0.408248 & 2.44949 \\
\hline PACKAGED V FAC REQ & 0.2 & 0.333333 & 0.166667 & 0.25 & 0.25 & 0.2 & 0.227568 & 4.39429 \\
\hline PACKAGED vS NOT DET & 0.142857 & 0.25 & 0.1111111 & 0.2 & 1 & 0.142857 & 0.22 & 4.545463 \\
\hline PACK REQ vs FAC REQ & 0.2 & 0.333333 & 0.25 & 0.25 & 2 & 0.25 & 0.357377 & 2.798166 \\
\hline PACK REQ VS NOT DET & 0.2 & 0.333333 & 0.166667 & 0.2 & 2) & 0.166667 & 0.3008 & 3.324469 \\
\hline FAC REQ VS NOT DET & 0.5 & 0.25 & 0.333333 & 0.25 & 3 & 0.2 & 0.429187 & 2.329986 \\
\hline \multicolumn{9}{|l|}{ STORAGE } \\
\hline STG AV VS MIN MODS & 1 & 0.333333 & 0.5 & 0.25 & 1 & 0.333333 & 0.49028 & 2.039649 \\
\hline STG AV VS MAJ MODS & 0.2 & 0.2 & 0.25 & 0.2 & 4 & 0.166667 & 0.331759 & 3.014233 \\
\hline MIN MODS vS MAJ MODS & 0.2 & 0.333333 & 0.333333 & 0.25 & 2 & 0.25 & 0.374929 & 2.667168 \\
\hline \multicolumn{9}{|l|}{ PROCNG } \\
\hline NOPRRA\&D vs MOD R\&D & 0.333333 & 0.5 & 0.333333 & 0.166667 & $\begin{array}{l}0.333333 \\
\end{array}$ & 0.5 & 0.339941 & 2.941683 \\
\hline NOPRRR\&D vs MAJ R\&D & 0.25 & 0.25 & 0.166667 & 0.142857 & 0.2 & 0.25 & 0.205085 & 4.876032 \\
\hline MOD R\&D vS MAJ R\&D & 0.333333 & 0.5 & 0.333333 & 0.166667 & 0.333333 & 0.5 & 0.339941 & 2.941683 \\
\hline \multicolumn{9}{|l|}{ WASTE FM } \\
\hline NOWR\&D Vs MODWR\&D & 0.333333 & 0.333333 & 0.333333 & 0.166667 & 0.333333 & 0.5 & 0.317728 & 3.147345 \\
\hline NOWR\&D Vs MAJWR\&D & 0.2 & 0.5 & 0.166667 & 0.142857 & 0.2 & 0.25 & 0.221796 & 4.50865 \\
\hline MODWR\&D VS MAWWR\&D & 0.2 & 0.333333 & 0.333333 & 0.166667 & 0.333333 & 0.5 & 0.291797 & 3.42704 \\
\hline
\end{tabular}




\section{Develop a ratings for attractiveness for using melt and dilute}

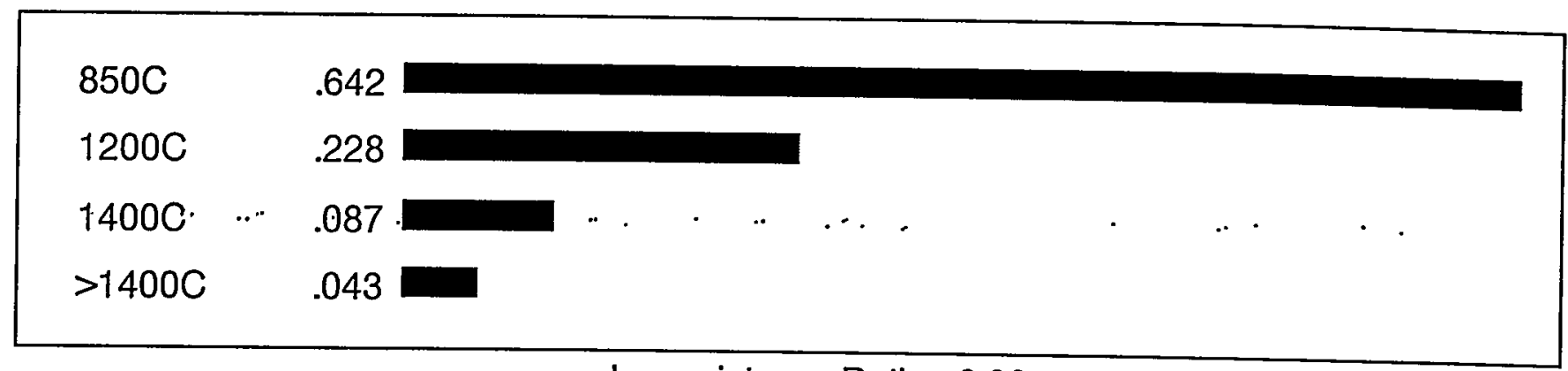

Inconsistency Ratio =0.09

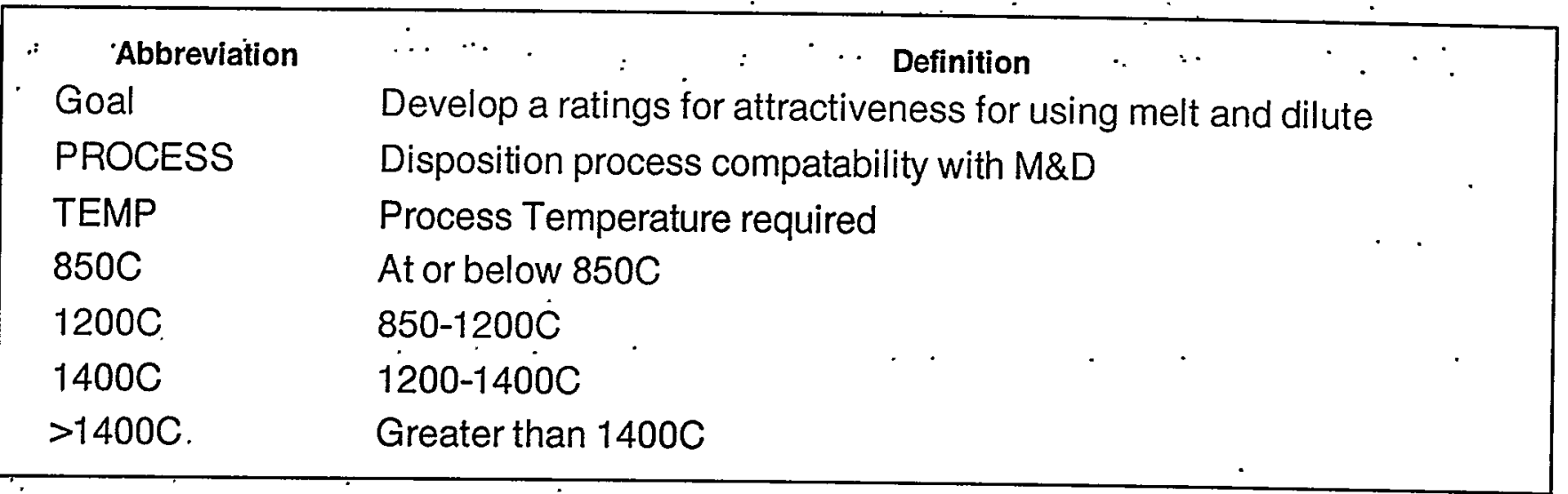




\section{Develop a ratings for attractiveness for using melt and dilute}

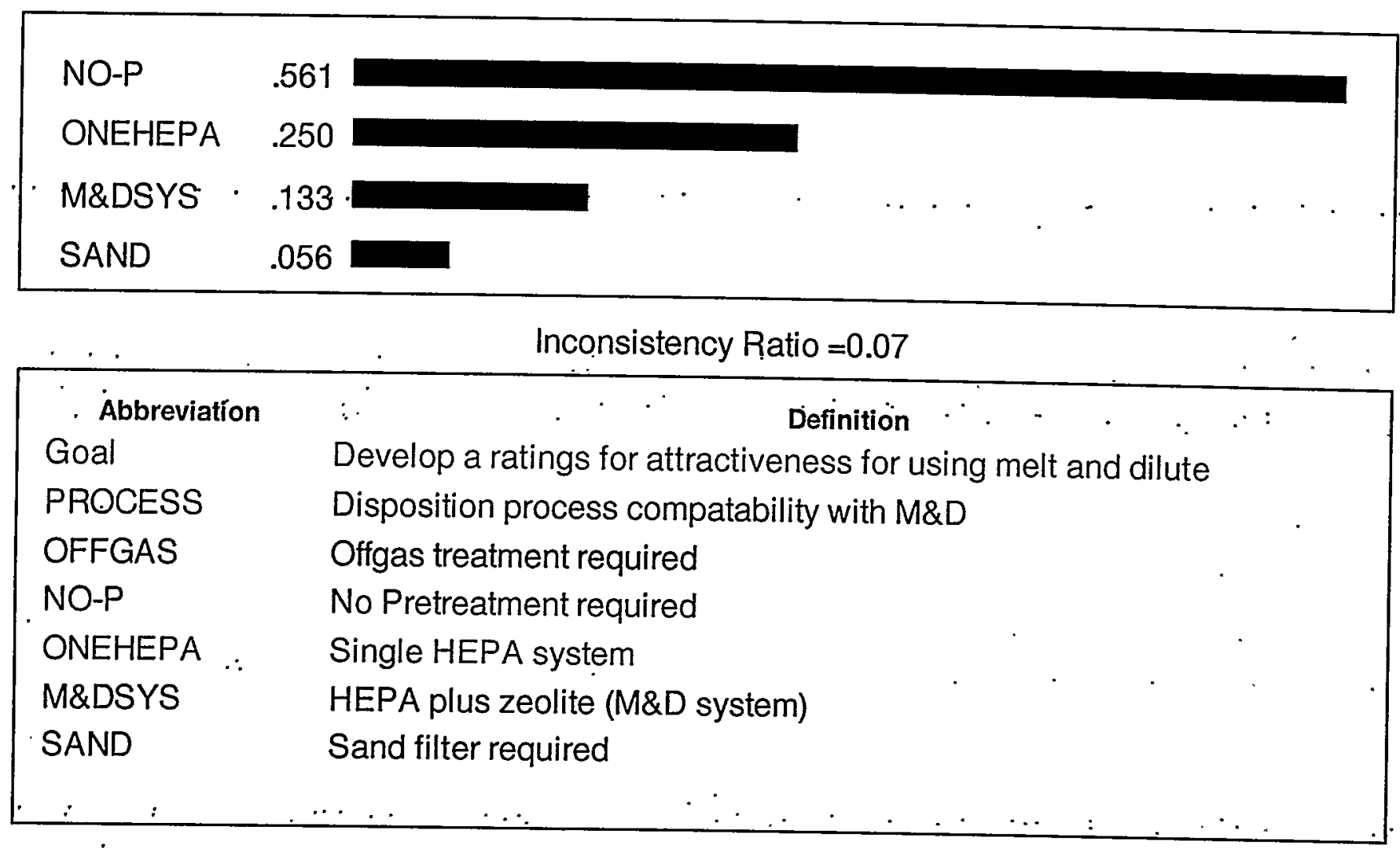




\section{Develop a ratings for attractiveness for using melt and dilute}



Inconsistency Ratio $=0.04$

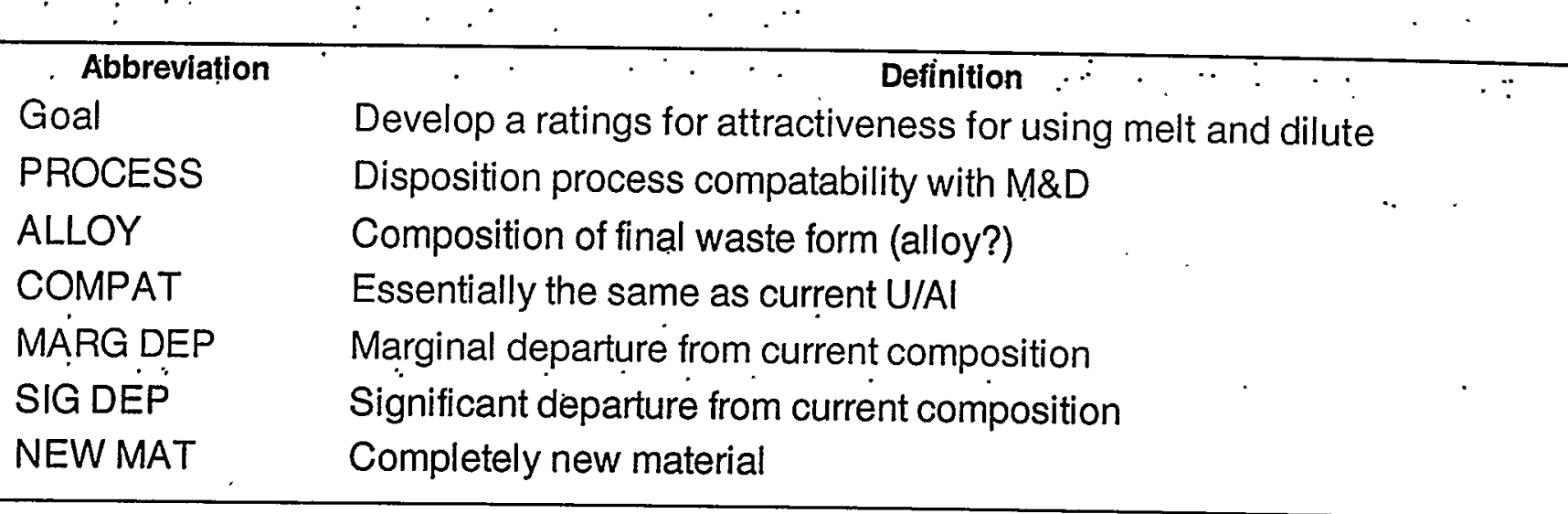




\section{Develop a ratings for attractiveness for using melt and dilute}

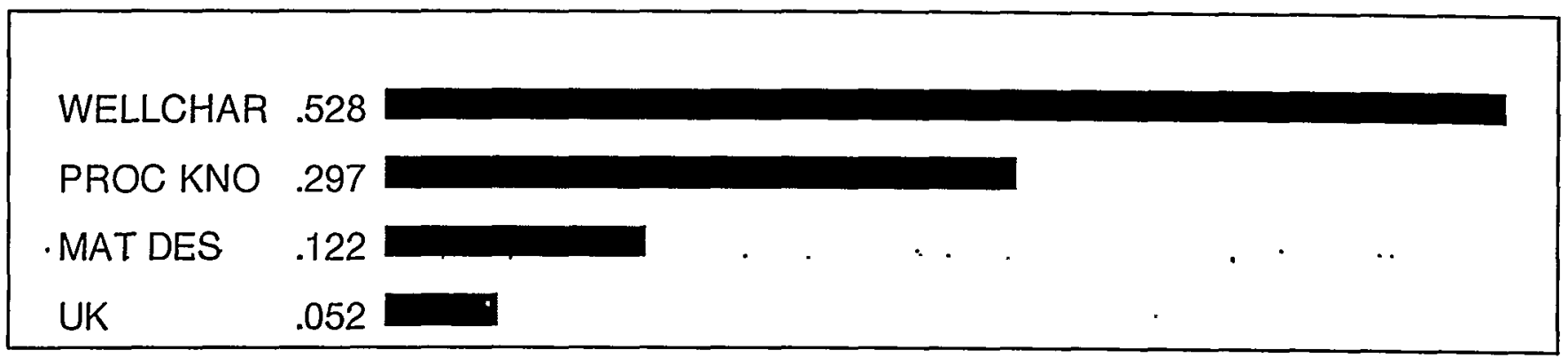

Inconsistency Ratio $=0.07$

\begin{tabular}{|ll|}
\hline \multicolumn{1}{|c|}{ Abbreviation } & \\
Goal & Develop a ratings for attractiveness for using melt and dilute \\
PROCESS & Disposition process compatability with M\&D \\
FEED & Knowledge of feed composition \\
WELLCHAR & Feed well characterized \\
P.ROC KNO & Process knowledge of feed available \\
MAT DES & Material has a description, some uncertainty \\
UK & Material composition substantially unknown \\
\hline
\end{tabular}




\section{Develop a ratings for attractiveness for using melt and dilute}

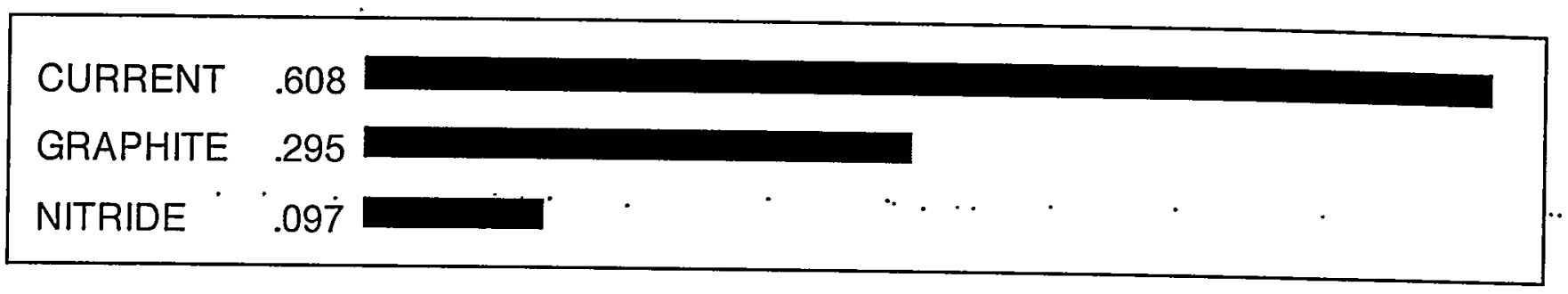

Inconsistency Ratio $=0.07$

Abbreviation

Goal.

PROCESS

MAT COMP

CURRENT

GRAPHITE

NITRIDE

\section{Définition.}

- Develop a ratings for attractiveness for using melt and dilute Disposition process compatability with M\&D Compatibilities of materials with equipment Steel crucible adequate Requires graphite crucible Requires silicon nitride or more exotic crucible 


\section{Develop a ratings for attractiveness for using melt and dilute}

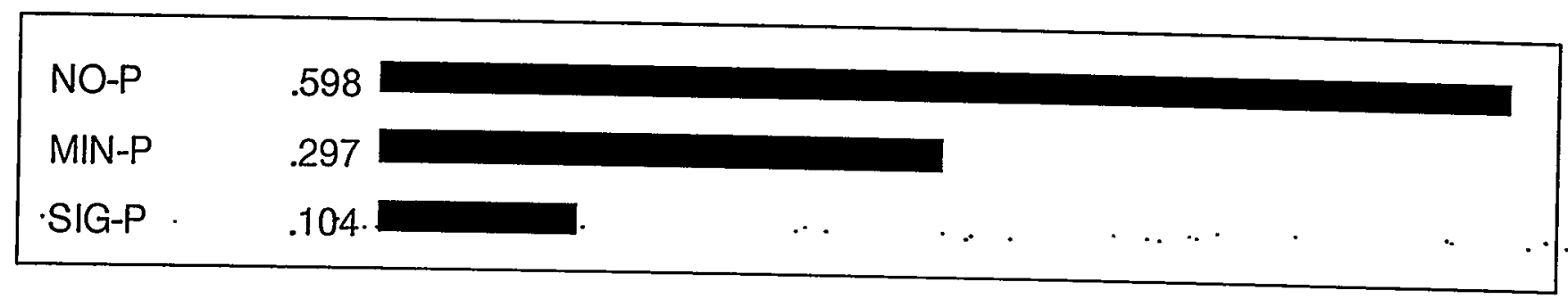

Inconsistency Ratio $=0.03$

\begin{tabular}{|c|c|}
\hline Abbreviation & Definition \\
\hline Goal " & Dévelop a ratings for attractiveness for using melt and dilute \\
\hline PROCESS & Disposition process compatability with M\&D \\
\hline PRETREAT & Levels of pretreatment required \\
\hline NO-P & No Pretreatment required \\
\hline MIN-P. & Minimal pretreatment (some sorting, minor size reduction) \\
\hline SIG-P & Significant pretreatment required.(compaction/cutting) \\
\hline
\end{tabular}




\section{Develop a ratings for attractiveness for using melt and dilute}

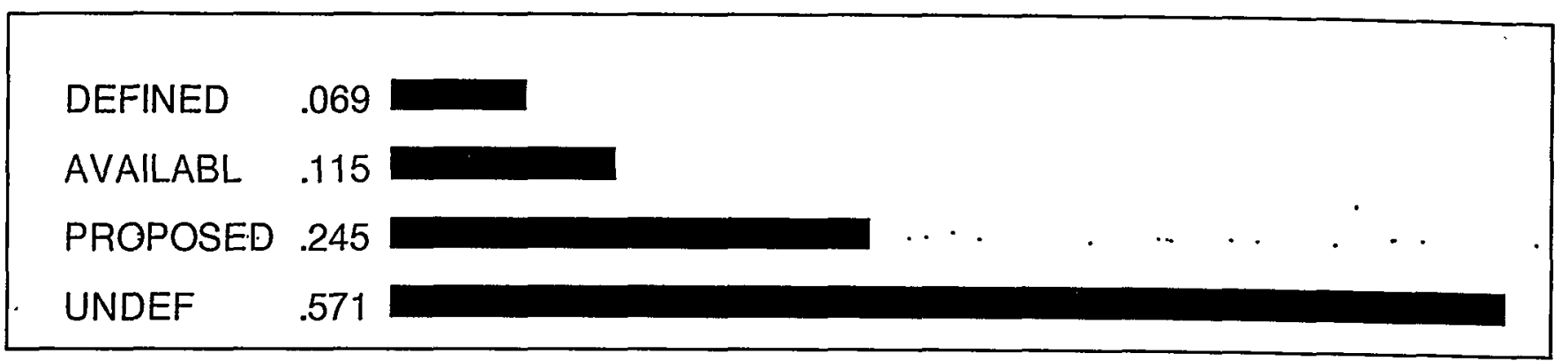

Inconsistency Ratio $=0.06$

\begin{tabular}{|llll}
\hline \multicolumn{1}{c}{ Abbreviation } & & \\
Goal & Develop a ratings for attractiveness for using melt and dilute & \\
DISPOSIT & Compatability of waste form with Yucca, WIPP, LLW etc. & \\
PATH AVL & Availability of current disposition path & \\
DEFINED & Path currently defined, available and funded & \\
AVAILABL & Path defined and available, not currently funded & & \\
PROPOSED & path developed, facilities and or funding not available & \\
UNDEF & Path not currently defined (TBD) \\
\hline
\end{tabular}


WSRC-TR-2000-00054

Develop a ratings for attractiveness for using melt and dilute

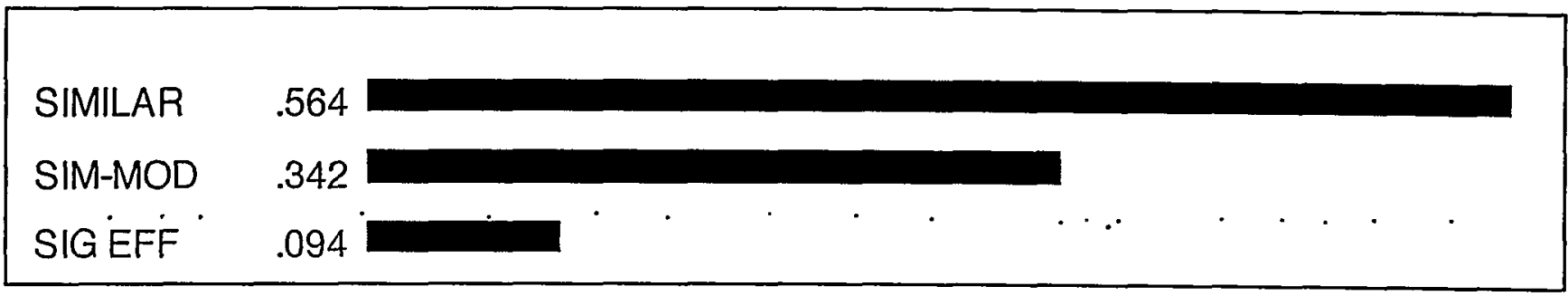

Inconsistency Ratio $=0.06$

\begin{tabular}{|ll|}
\hline \multicolumn{1}{|c|}{ Abbreviation } & \multicolumn{1}{c|}{ Definition } \\
Goal & Develop a ratings: for attractiveness for using mèlt and dilute \\
DISPOSIT & Compatability of waste form with Yucca, WIPP, LLW etc. \\
ATTRACTV & Attractiveness of waste form; ease of certification \\
SIMILAR & Very similar to M\&D form or no issues \\
SIM-MOD & Similar with minor modifications to testing \\
SIG EFF & Requires significant waste form qualification effort \\
\hline
\end{tabular}




\section{Develop a ratings for attractiveness for using melt and dilute}

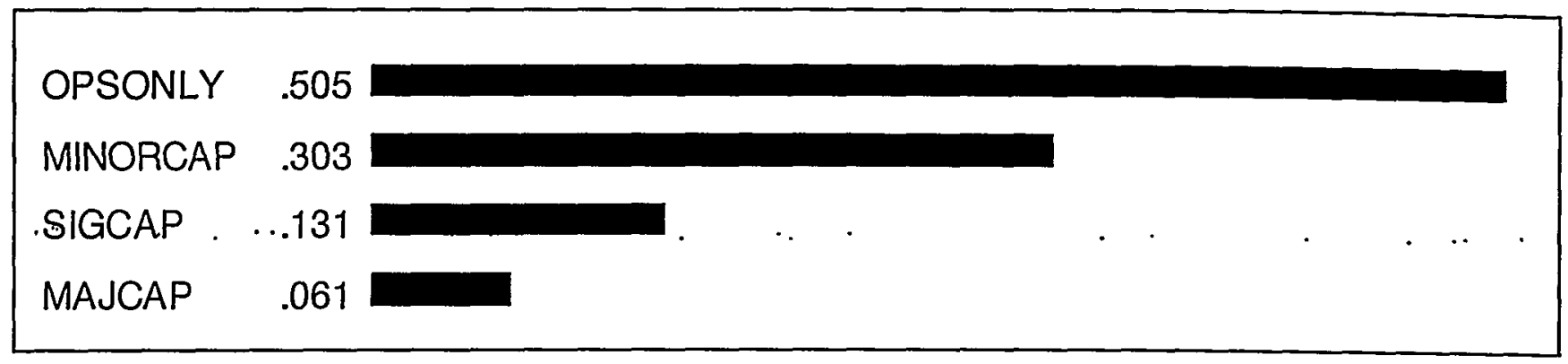

Inconsistency Ratio $=0.06$

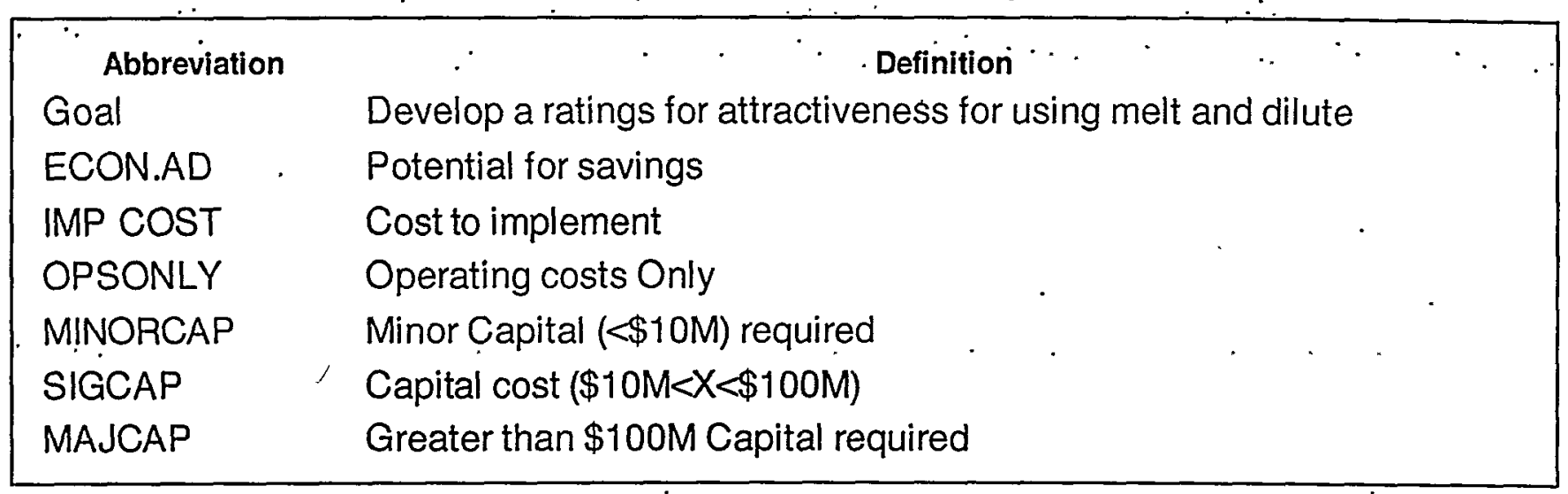




\section{Develop a ratings for attractiveness for using melt and dilute}

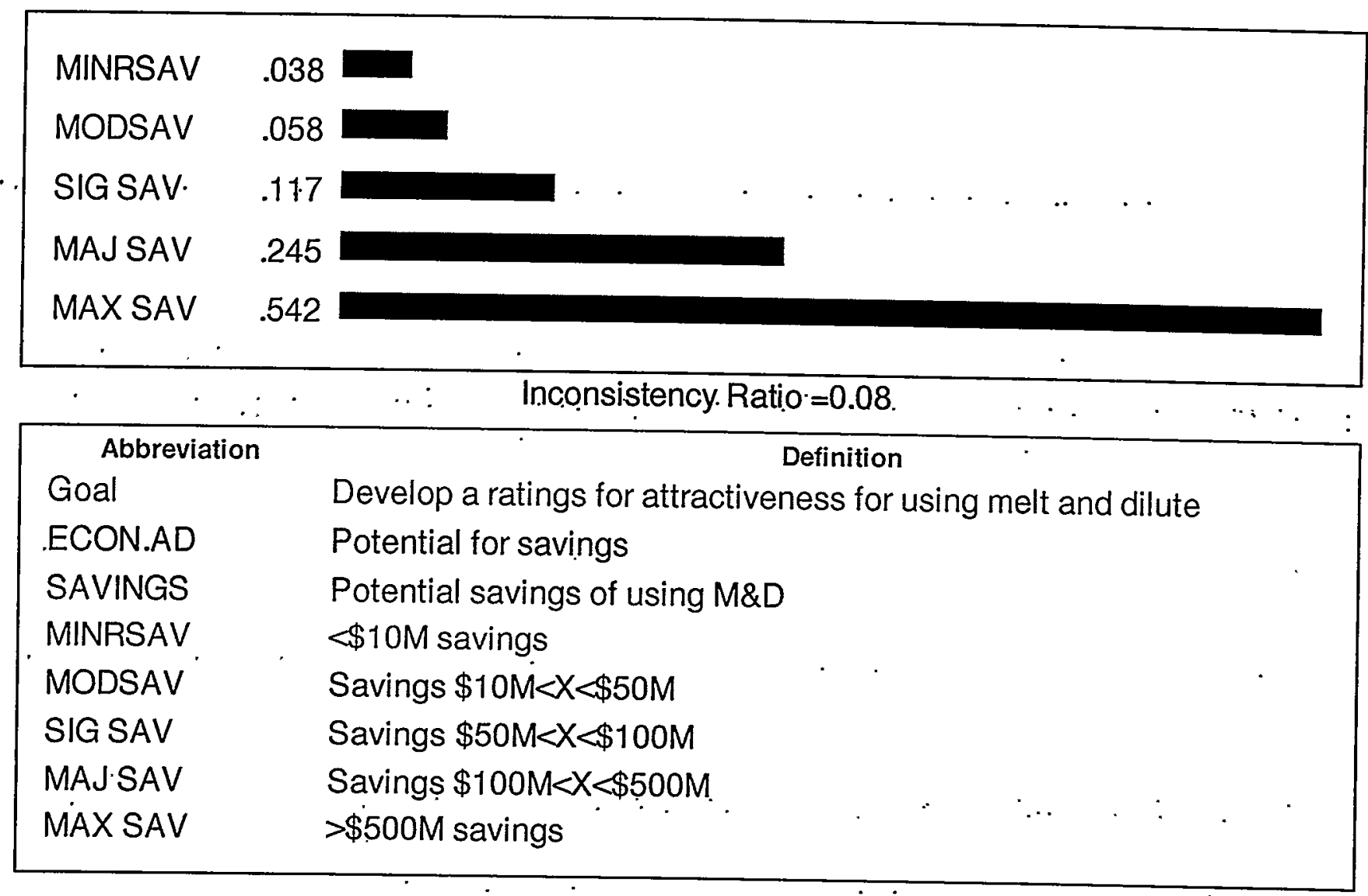




\section{Develop a ratings for attractiveness for using melt and dilute}

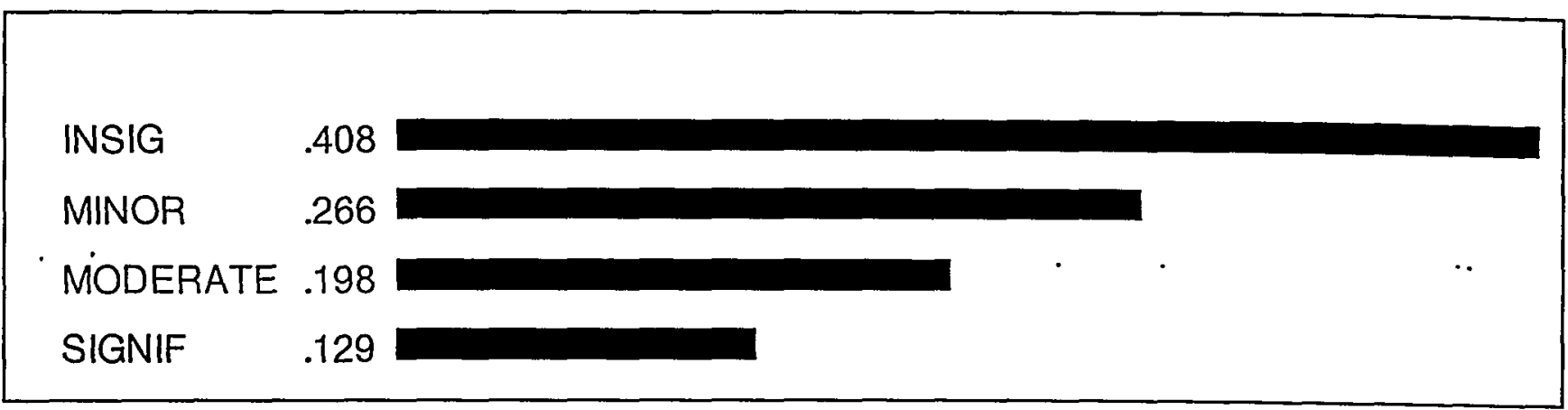

Inconsistency Ratio $=0.04$

\begin{tabular}{|ll}
\hline \multicolumn{1}{c}{ Abbreviation } & Develop a ratings for attractiveness for using melt and dilute \\
Goal & Potential for savings \\
ECON.AD & Quantity of material to be processed (months) \\
QUANTITY & $<1$ Month processing \\
INSIG & Process Time $=1$ Month $<X<6$ Months \\
MINOR & Processing Time 6 Months $<X<12$ Months \\
MODERATE & Greater than 12 Months processing required \\
SIGNIF &
\end{tabular}




\section{Develop a ratings for attractiveness for using melt and dilute}

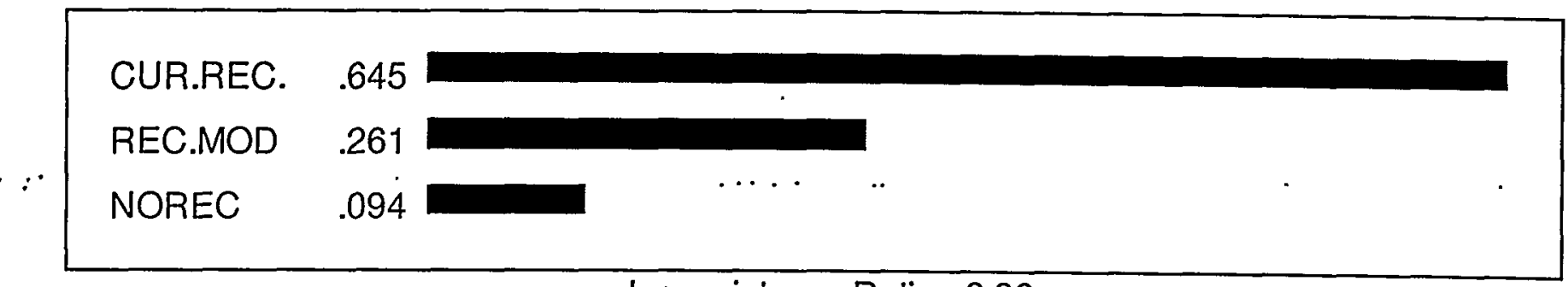

Inconsistency Ratio $=0.06$

\begin{tabular}{|c|c|}
\hline Abbreviation & Definition \\
\hline Goal .. & Develop a ratings for attractiveness for using melt and dilute \\
\hline TRNSPRT & Ability to ship and receive \\
\hline RECEIVNG & Ability to receive material \\
\hline CUR.REC. & Receiving capability current \\
\hline REC.MOD & Receiving requires mods \\
\hline NOREC & No Receiving capability \\
\hline
\end{tabular}


WSRC-TR-2000-00054

\section{Develop a ratings for attractiveness for using melt and dilute}

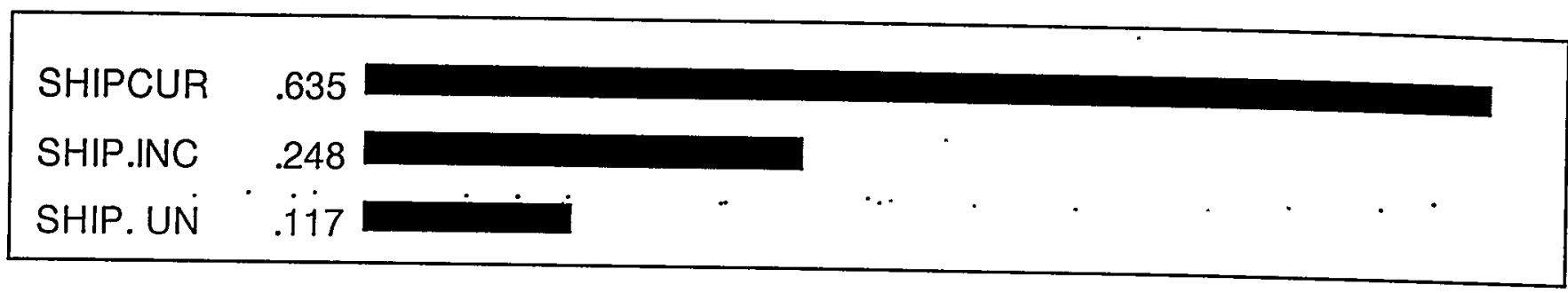

Inconsistency Ratio $=0.01$

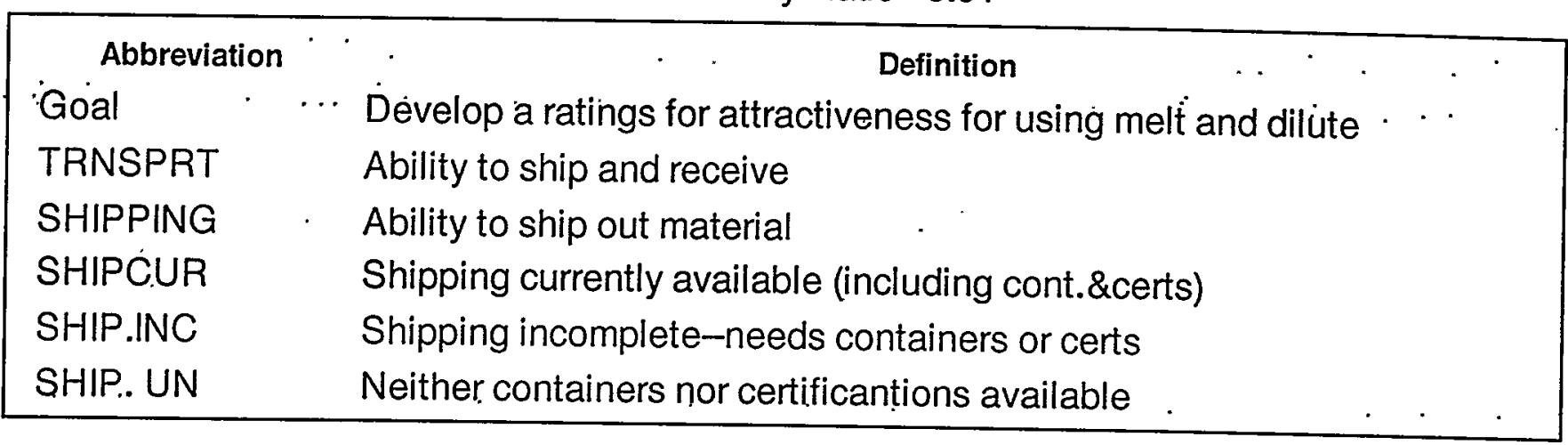




\section{Develop a ratings for attractiveness for using melt and dilute}

\section{PACKAGED .515 \\ PACK REQ $\quad .274$ \\ FAC REQ $\quad \cdot .130$ \\ NOT DET $\quad .082$}

$$
\text { Inconsistency Ratio }=0.04
$$

\begin{tabular}{ll}
\multicolumn{1}{c}{ Abbreviation } & \\
Goal & Develop a ratings for attractiveness for using melt and dilute \\
TRNSPRT & Ability to ship and receive \\
PCKGING & Shipping prepations required. \\
PACKAGED & Material is packaged for shipping \\
PACK REQ & Packaging is required \\
FAC REQ & Packaging facilities required \\
NOT DET & Packaging requirements not determined
\end{tabular}




\section{Develop a ratings for attractiveness for using melt and dilute}




WSRC-TR-2000-00054

\section{Develop a ratings for attractiveness for using melt and dilute}



Inconsistency Ratio $=0.03$

Abbreviation

Définition

Goal . : . D Develop a ratings for attractiveness for using melt and dilute

TECH DEV Technology Development Required

$P R O C N G \quad$ Additional process $R \& D$ required.

NOPRR\&D No Processing $R \& D$ required (in scope of current pgm)

MOD R\&D Moderate Process $R \& D$ required

MAJ R\&D . Major process R\&D required 


\section{Develop a ratings for attractiveness for using melt and dilute}

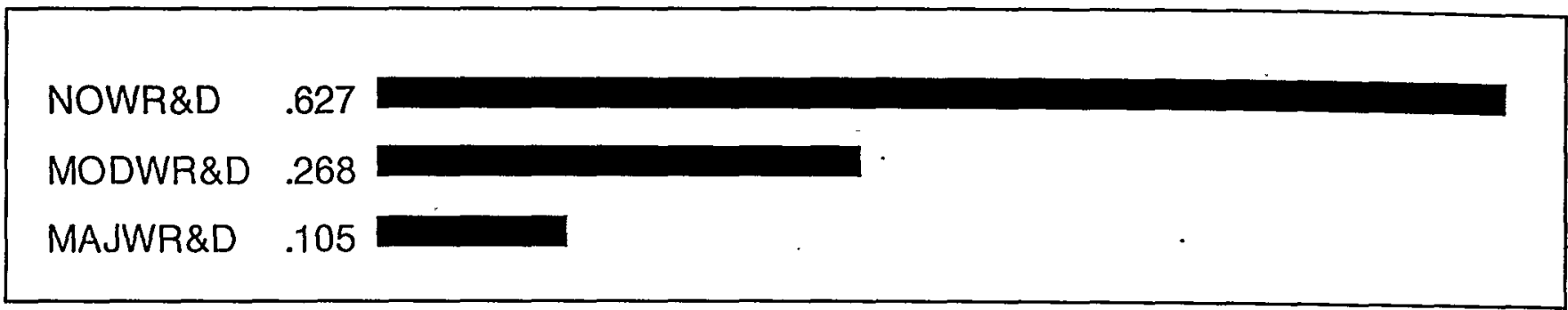

Inconsistency Ratio $=0.08$

\section{Abbreviation} Goal $\cdot \cdot$. TECH DEV Technology Development Required WASTE FM Additional waste form $R \& D$ required. NOWR\&D No additional Waste Form R\&D Required MODWR\&D Moderate Waste form $R \& D$ required MAJWR\&D Major Waste form $R \& D$ required, New 
APPENDIX D

MATERIALS RATINGS

D-1 
WSRC-TR-2000-00054

This page intentionally left blank 


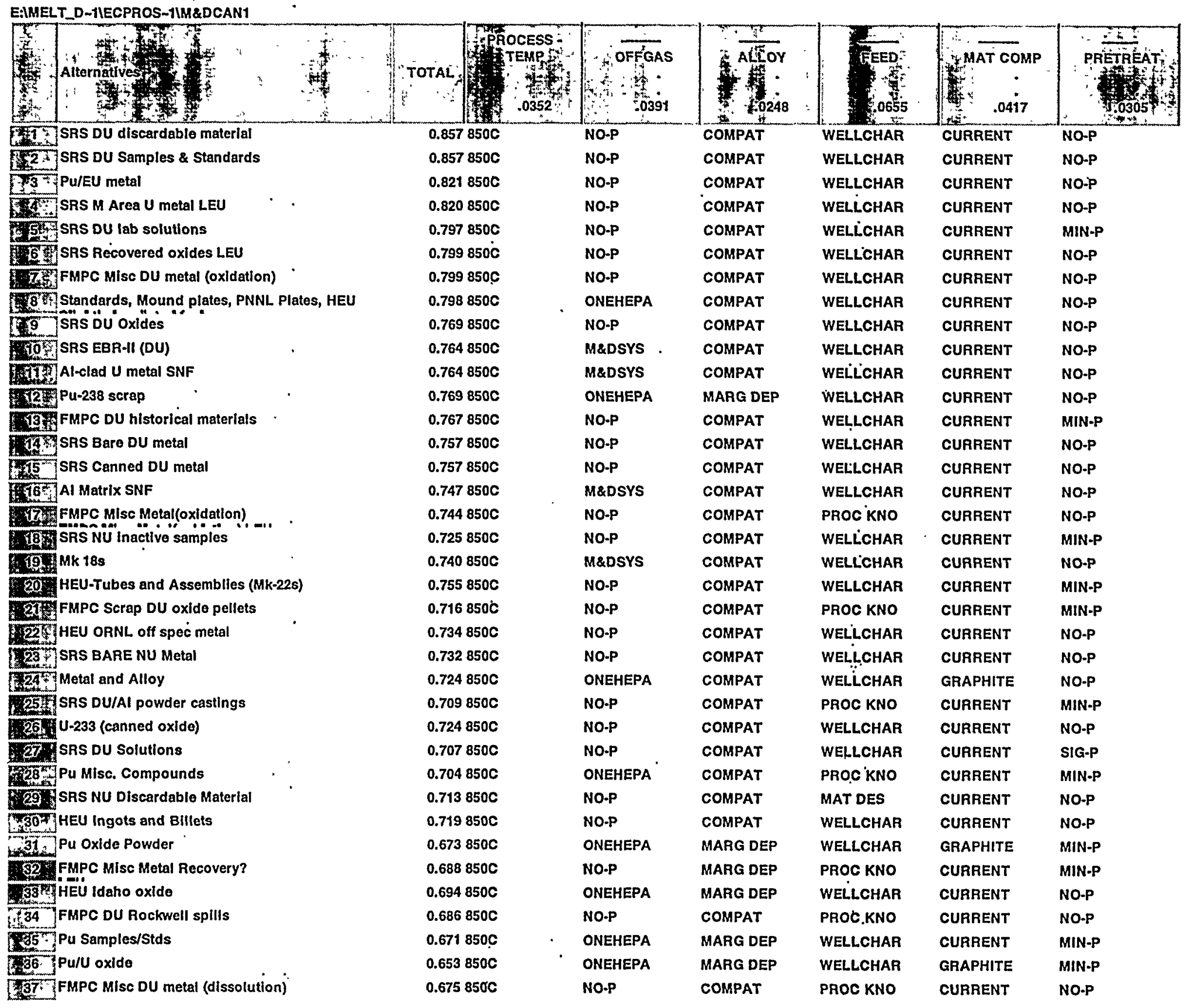




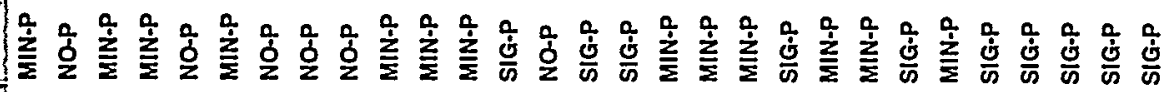

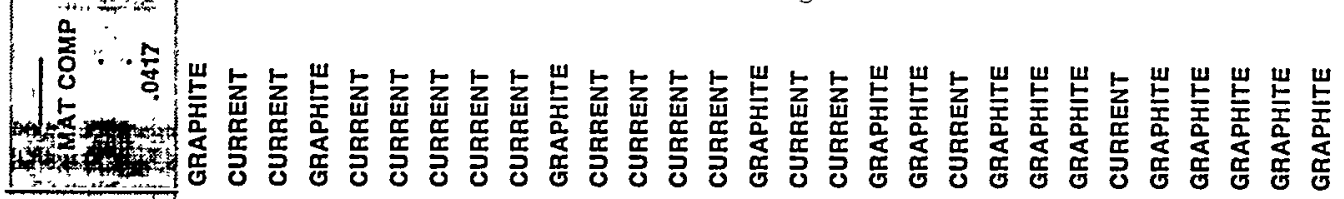



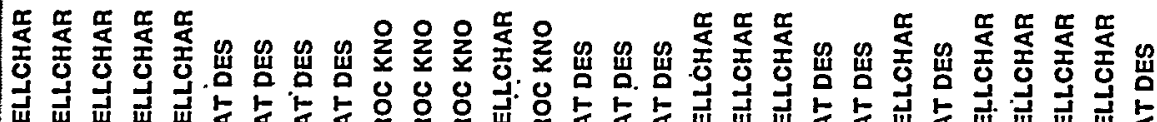

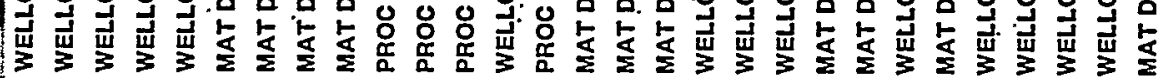

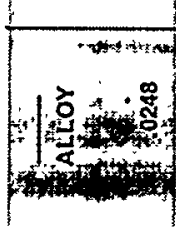



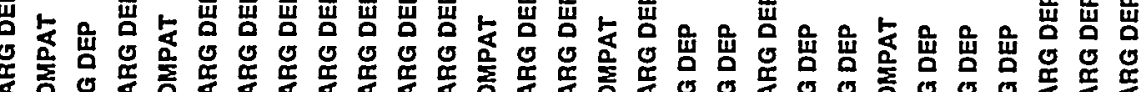
校

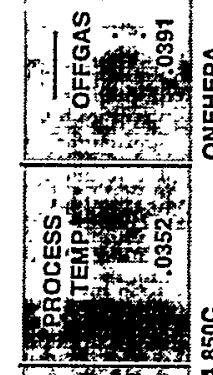

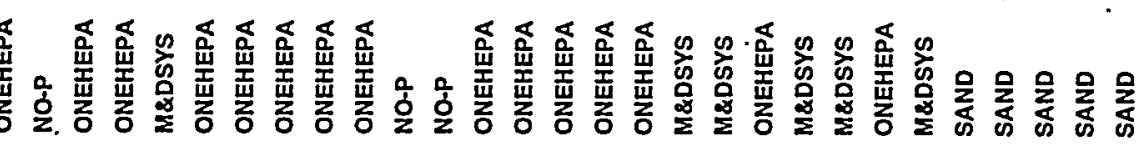

\section{(n)}




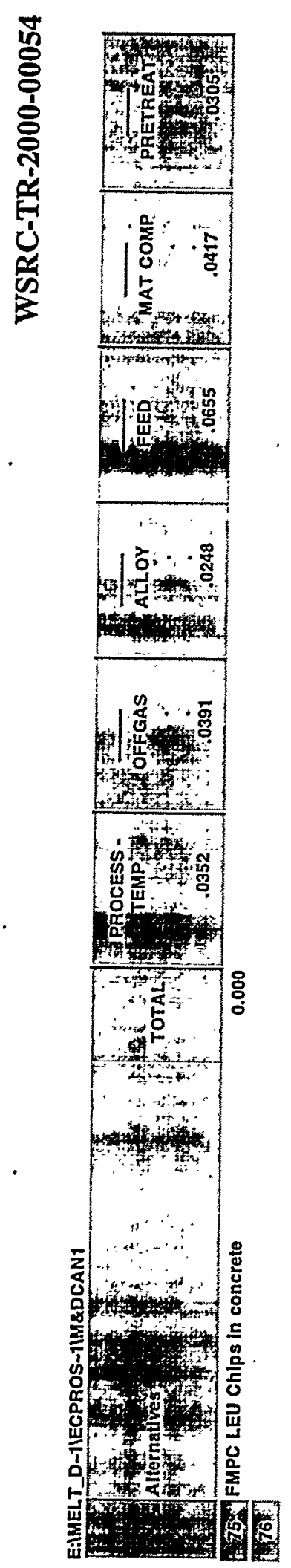


WSRC-TR-2000-00054

\begin{tabular}{|c|c|c|c|c|c|c|c|}
\hline 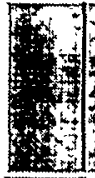 & 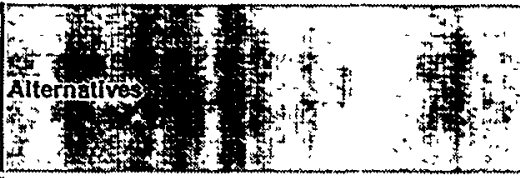 & 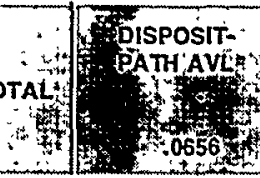 & 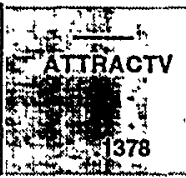 & 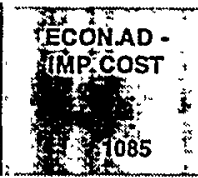 & 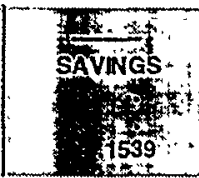 & 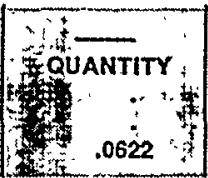 & 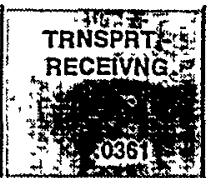 \\
\hline This & SRS DU discardable material & 0.857 UNDEF & SIMILAR & OPSONLY & MINRSAV & INSIG & CUR.REC. \\
\hline 23 & SRS DU Samples \& Standards & 0.857 UNDEF & SIMILAR & OPSONLY & MINRSAV & INSIG & CUR.REC. \\
\hline 3. & Pu/EU metal & 0.821 PROPOSED & SIM-MOD & OPSONLY & MAX SAV & MODERATE & REC.MOD \\
\hline D:4 & SRS M Area U metal LEU & 0.820 PROPOSED & SIMILAR & OPSONLY & MINRṢAV & INSIG & CUR.REC. \\
\hline 59 & SRS DU lab solutions & 0.797 UNDEF & SIMILAR & OPSONLY & MINRSAV & INSIG & CUR.REC. \\
\hline $5 \times 6$ & SRS Recovered oxides LEU & 0.799 DEFINED & SIMILAR & OPSONLY & MINRSAV & INSIG & CUR.REC. \\
\hline -74 & FMPC Misc DU metal (oxidatlon) & 0.799 DEFINED & SIMILAR & OPSONLY. & MINASAV & INSIG & CUR.REC. \\
\hline 88 & Standards, Mound plates, PNNL Plate & 0.798 PROPOSED & SIMILAR & OPSONLY & MINRSAV & INSIG & CUR.REC. \\
\hline 29 & SRS DU Oxides & 0.769 UNDEF & SIMILAR & OPSONLY & MINRSAV & SIGNIF & CUR.REC. \\
\hline 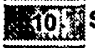 & SRS EBR-\|l (DU) & 0.764 PROPOSED & SIMILAR & OPSONLY & MODSAV & MODERATE & CUR.REC. \\
\hline (1) & Al-clad U metal SNF & 0.764 PROPOSED & SIMILAR & OPSONLY & MODSAV & MODERATE & CUR.REC. \\
\hline 212 & Pu-238 scrap & 0.769 UNDEF & SIMILAR & OPSONLY & MINASAV & INSIG & REC.MOD \\
\hline $43^{3}$ & FMPC DU historical materials & 0.767 UNDEF & SIMILAR & OPSONLY & MINRṢAV & INSIG & CUR.REC. \\
\hline 14T3 & SRS Bare DU metal & 0.757 DEFINED & SIMILAR & OPSONLY & MINASAV & SIGNIF & CUR.REC. \\
\hline $6+5$ & SRS Canned DU metal & 0.757 DEFINED & SIMILAR & OPSONLY & MINASAV & SIGNIF & CUR.REC. \\
\hline 16 & Al Matrix SNF & 0.747 PROPOSED & SIMILAR & OPSONLY & MINASAV & SIGNIF & CUR.REC. \\
\hline 17:? & FMPC Misc Metal(oxidation) _... & 0.744 PROPOSED & SIMILAR & OPSONLY & MINASAV & iNSIG & REC.MOD \\
\hline 18 & SRS NU inactive samples & 0.725 DEFINED & SIMILAR & OPSONLY & MINRSAV & INSIG & CUR.REC. \\
\hline (19) & Mk 18s & 0.740 PROPOSED & SIMILAR & OPSONLY & MODSAV & INSIG & REC.MOD \\
\hline 201 & HEU-Tubes and Assemblles (Mk-22s) & 0.755 PROPOSED & SIMILAR & OPSONLY & SIG.SAV & SIGNIF & CUR.REC. \\
\hline 216 & FMPC Scrap DU oxide pellets & 0.716 DEFINED & SIMILAR & OPSONLY & MODSAV & INSIG & CUR.REC. \\
\hline 221 & HEU ORNL off spec metal & 0.734 DEFINED & SIMILAR & OPSONLY & MINhịșaV & SIGNIF & CUR.REC. \\
\hline 2374 & SAS BARE NU Motal & 0.732 PROPOSED & SIMILAR & OPSONLY & MINẠSAV & MODERATE & REC.MOD \\
\hline $24 \pi$ & Metal and Alloy & 0.724 PROPOSED & SIM-MOD & MINORCAP & MAX.SAV & SIGNIF & REC.MOD \\
\hline 2516 & SRS DU/AI powder castings & 0.709 PROPOSED & SIMILAR & OPSONLY & MINRSAV & MINOR & CUR.REC. \\
\hline 2614 & U-233 (canned oxide) & 0.724 PROPOSED & SIMILAR & OPSONLY & MINRSAV & MODERATE & AEC.MOD \\
\hline 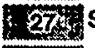 & SAS DU Solutions ' & 0.707 PROPOSED & SIMILAR & OPSONLY & MINASAV & SIGNIF & CUR.REC. \\
\hline 28 & Pu Misc. Compounds & 0.704 UNDEF & SIM-MOD & MINORCAP & MAX, SAV & MODERATE & REC.MOD \\
\hline 29 & SRS NU Discardable Material & 0.713 PROPOSED & SIMILAR & OPSONLY & MIN!ASAV & INSIG & REC.MOD \\
\hline$\sqrt{30}$ & HEU ingots and Blllets & 0.719 AVAILABL & SIMILAR & OPSONLY & MINRSAV & SIGNIF & CUR.REC. \\
\hline 31 & Pu Oxide Powder & 0.673 PROPOSED & SIM-MOD & MINORCAP & MAX.SAV & MINOR & REC.MOD \\
\hline$E_{32}$ & FMPC Misc Metal Recovery? & 0.688 PROPOSED & SIMILAR & OPSONLY & MINRSAV & MINOR & REC.MOD \\
\hline 233 & HEU Idaho oxide & 0.694 UNDEF & SIMILAR & OPSONLY & MODSAV & MODERATE & REC.MOD \\
\hline 34 & FMPC DU Rockwell spills & 0.686 UNDEFF & SIMILAR & OPSONLY & MINRSAV & MINOR & REC.MOD \\
\hline 235. & Pu Samples/Stds & 0.671 PROPOSED & SIM-MOD & OPSONLY & MINRSAV & INSIG & REC.MOD \\
\hline $36 \div$ & Pu/U oxide & 0.653 PROPOSED & SIM-MOD & MINORCAP & MAX SAV & SIGNIF & REC.MOD \\
\hline $837+2$ & FMPC Misc DU metal (dissolution) & 0.675 UNDEF & SIMILAR & OPSONLY & MINRSAV & MODERATE & REC.MOD \\
\hline
\end{tabular}


WSRC-TR-2000-00054

\begin{tabular}{|c|c|c|c|c|c|c|c|}
\hline 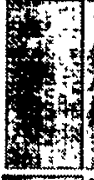 & 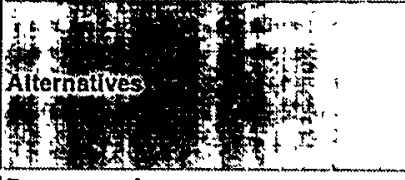 & 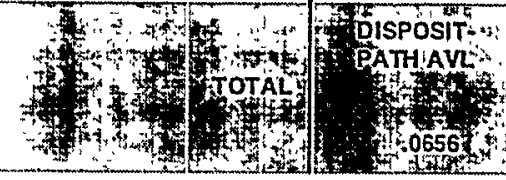 & 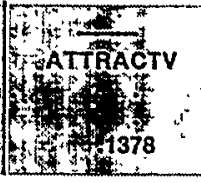 & $\begin{array}{l}\text { ECONAD - } \\
\text { IMPCOST } \\
\\
\end{array}$ & 5 & 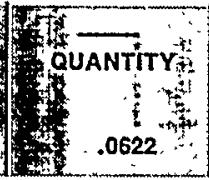 & 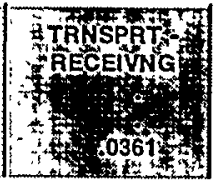 \\
\hline Waban & Pu scrap mlsc & 0.644 PROPOSED & SIM-MOD & MINORCAP & MAX SAV & SIGNIF & REC.MOD \\
\hline 896 & HEU Hanford & 0.663 PROPOSED & SIMILAR & OPSONLY & MODSAV & MODERATE & REC.MOD \\
\hline $40^{\circ}$ & ZPPR plates & 0.629 PRROPOSED & SIM-MOD & SIGCAP & MAX SAV & SIGNIF & REC.MOD \\
\hline 4619 & Pu Mixed Oxide Slugs & 0.644 PROPOSED & SIM-MOD & MINORCAP & MAX SAV & MINOR & REC.MOD \\
\hline 4429 & U-233/SNF & 0.647 PROPOSED & SIMILAR & OPSONLY. & MINRSAV & MINOR & REC.MOD \\
\hline 843 & Pu Ash & 0.642 UNDEF & SIM-MOD & MINORCAP & MAX SAV & INSIG & REC.MOD \\
\hline 1448 & Cm 244 solution & 0.646 UNDEF & SIM-MOD & OPSONLY & MINASAV & INSIG & CUR.REC. \\
\hline $45^{3}$ & Am 243 oxide & 0.646 UNDEF & SIM-MOD & OPSONLY & MINRSAV & INSIG & CUR.REC. \\
\hline 246 & Am 241 samples/stds & 0.646 UNDEF & SIM-MOD & OPSONLY & MINASAV & INSIG & CUR.REC. \\
\hline 6474 & U/Pu/Zr Castlng Scrap & 0.620 UNDEF & SIM-MOD & MINORCAP & MAX SAV & MODERATE & REC.MOD \\
\hline [88 & FMPC Rockwell spllls LEU & 0.592 PROPOSED & SIMILAR & MINORCAP & MINRSAV & INSIG & REC.MOD \\
\hline 449 & FMPC MIsc LEU Metal(dissolution) & 0.592 PROPOSED & SIMILAR & MINORCAP & MINRSAV & INSIG & REC.MOD \\
\hline 560: & HEU SRS Solutions & 0.581 PROPOSED & SIMILAR & SIGCAP & MODSAV & SIGNIF & CUR.REC. \\
\hline E51 & SRS NU (Pu) Scrap & 0.574 PROPOSED & SIM-MOD & OPSONLY & MINASAV & INSIG & REC.MOD \\
\hline 552 & Pu Chlorides, flourides etc & 0.566 UNDEF & SIM-MOD & SIGCAP & MAX SAV & MINOR & REC.MOD \\
\hline t53.5 & Pu Combustlbles & 0.552 UNDEF. & SIM-MOD & MINORCAP & SIG SAV & MODERATE & REC.MOD \\
\hline 954 & SRS DU Sludge and Filter Cake & 0.565 UNDEF & SIM-MOD & MINORCAP & MINRSAV & MINOR & CUR.REC. \\
\hline 555 & SRS DU SS/Zr fuel/targets & 0.539 PROPOSED & SIM-MOD & MINORCAP & MINRSAV & INSIG & CUR.REC. \\
\hline 567 & SRS Pu/DU OxIde fuel rods & 0.539 PROPOSED & SIM-MOD & MINORCAP & MINRSAV & INSIG & CUR.REC. \\
\hline 57 & Np 237 scrap & 0.517 UNDEF & SIM-MOD & MINORCAP & MINRSAV & MODERATE & REC.MOD \\
\hline S58, & SRS Pu/DU scrap & 0.489 PROPOSED & SIM-MOD & MINORCAP & MINRSAV & INSIG & CUR.REC. \\
\hline 59 & FMPC DU Nonburnable metal & 0.471 UNDEF & SIM-MOD & MINORCAP & MINRSAV & INSIG & REC.MOD \\
\hline $660 \%$ & Pu-239 Pits & 0.457 PROPOSED & S.M-MOD & MINORCAP & MODSAV & SIGNIF & NOREC \\
\hline B61 & FMPC DU lead contaminated & 0.410 UNDEF & SIG EFF & MINORCAP & MINASAV & MINOR & REC.MOD \\
\hline 62 & Metal U-Zr SNF & 0.338 PROPOSED & SIM-MOD & SIGCAP & MINRSAV & MODERATE & NOREC \\
\hline 6635 & Metal(U,U-Mo)/Na SNF & 0.338 PROPOSED & SIM-MOD & SIGCAP & MINRSAV & MODERATE & NOREC \\
\hline 694 & Oxide-Research SNF & 0.310 PROPOSED & SIM-MOD & MAJCAP & MINRSAV & SIGNIF & NOREC \\
\hline 65 & Oxide-Commerclal SNF. & 0.305 DEFINED & SIM-MOD & SIGCAP & MIN!RSAV & SIGNIF & NOREC \\
\hline 666 & Oxide Disrupted TMI SNF & 0.270 PROPOSED & SIM-MOD & MAJCAP & MINRSAV & SIGNIF & NOREC \\
\hline 5677 & Oxide, U/Th SNF & 0.000 & & & 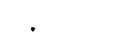 & & \\
\hline 68. & FMPC Chips in concrete LEU & 0.000 & & & & & \\
\hline 69 & SRS Vitrifled waste LEU & 0.000 & & & & & \\
\hline Sop & FMPC DU chips in concrete & 0.000 & & & & & \\
\hline 79 & Graphite SNF & 0.000 & & & & & \\
\hline 828 & Misc Other SNF & 0.000 & & & & & \\
\hline 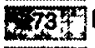 & Misc Other (failed) & 0.000 & & & - & & \\
\hline $1043^{3}$ & Irradiated Reactor Parts & 0.000 & & & & & \\
\hline
\end{tabular}

D-7 


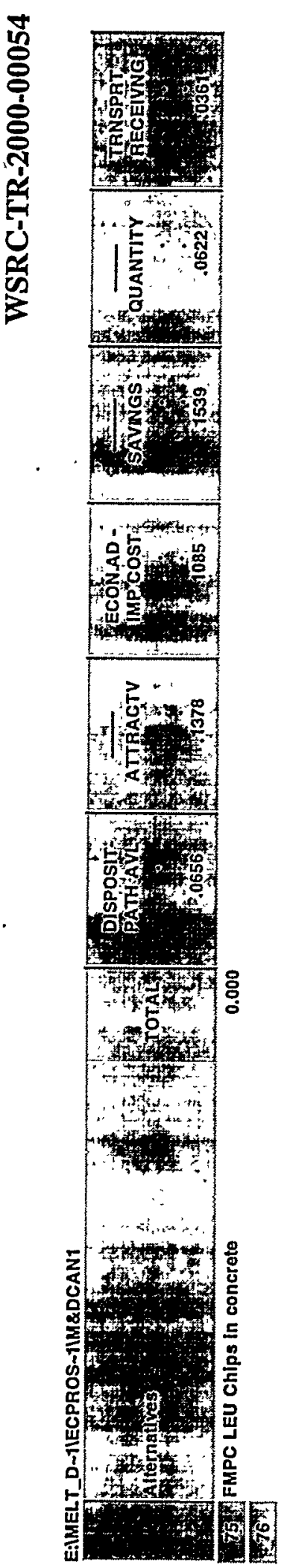

$\stackrel{\infty}{\circ}$ 


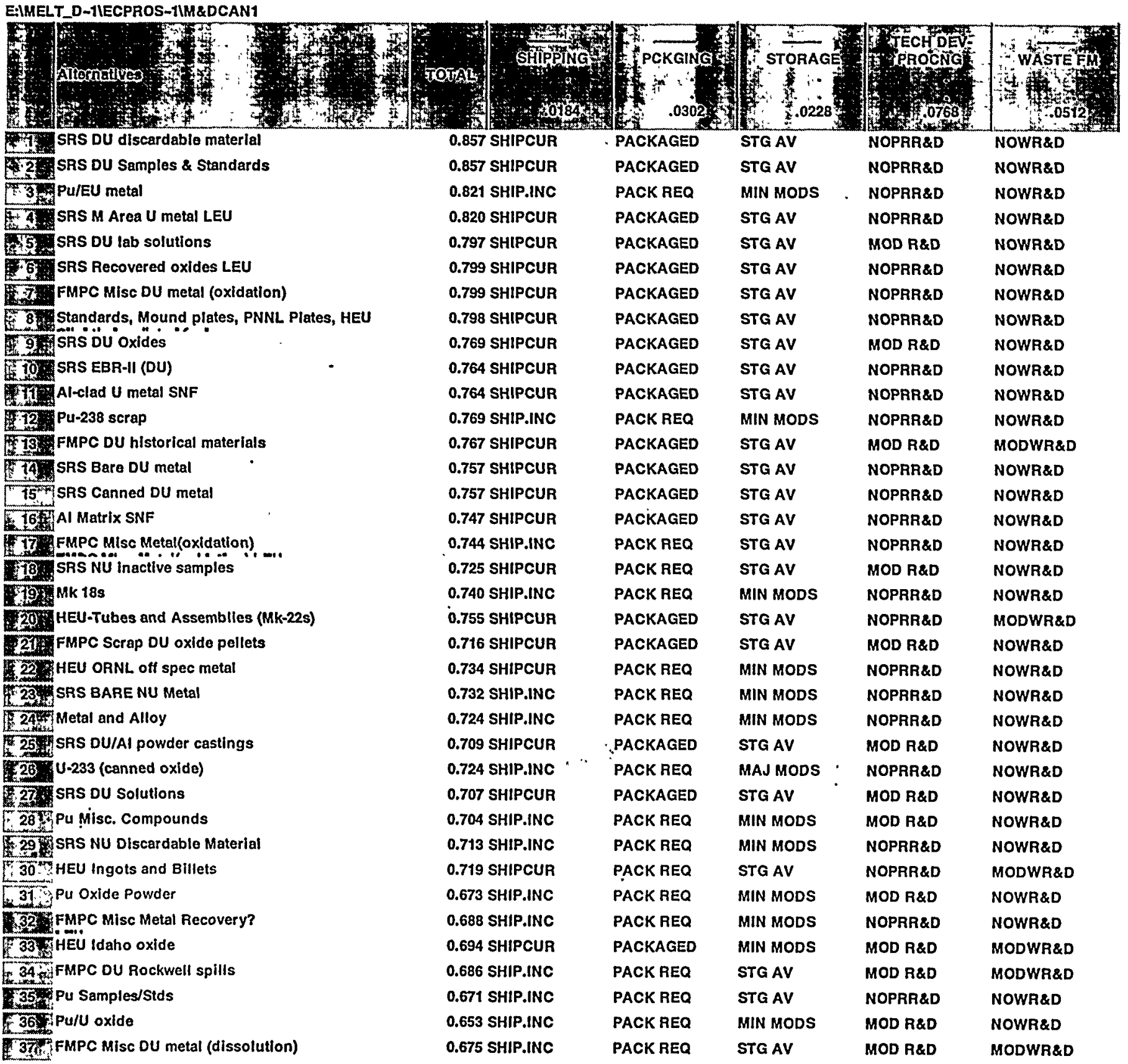


WSRC-TR-2000-00054

\begin{tabular}{|c|c|c|c|c|c|c|}
\hline  & 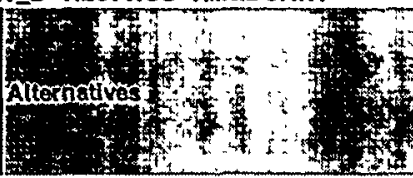 & orat & 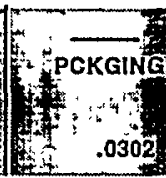 & 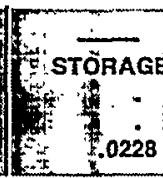 & 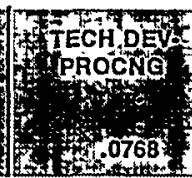 &  \\
\hline 58 & Pu scrap mlsc & 0.644 SHIP.INC & FAC REQ & MIN MODS & MOD R\&D & NOWR\&D \\
\hline -392 & HEU Hanford & 0.663 SHIP.INC & PACK REQ & MIN MODS & MOD R\&D & MODWR\&D \\
\hline .406 & ZPPR plates & 0.629 SHIP.INC & PACK REQ & MIN MODS & MOD R\&D & NOWR\&D \\
\hline i41) & Pu Mixed Oxide Slugs & 0.644 ŚHIP.INC & PACK REQ & MIN MODS & MOD R\&D & MODWR\&D \\
\hline .42 & U-233/SNF & 0.647 SHIP.INC & PACK REQ & STG AV & MOD R\&D & MODWR\&D \\
\hline 043 & Pu Ash & 0.642 SHIP.INC & PACK REQ & MIN MODS & MAJ R\&D & MAJWR\&D \\
\hline (54) & $\mathrm{Cm} 244$ solution & 0.646 SHIPCUR & PACKAGED & STG AV & MOD R\&D & MODWR\&D \\
\hline (245) & Am 243 oxido & 0.646 SHIPCUR & PACKAGED & STG AV & MOD R\&D & MODWR\&D \\
\hline 446 & Am 241 samples/stds & 0.646 SHIPCUR & PACKAGED & STG AV & MOD R\&D & MODWR\&D \\
\hline 47 & U/Pu/Zr Casting Scrap & 0.620 SHIP.INC & PACK REQ & MIN MODS & MOD R\&D & MODWR\&D \\
\hline 488 & FMPC Rockwell spills LEU & 0.592 SHIP.INC & PACK REQ & MIN MODS & MOD R\&D & MODWR\&D \\
\hline 049 & FMPC Misc LEU Metal(dissolution) & 0.592 SHIP.INC & PACK REQ - & MIN MODS & MOD R\&D & MODWR\&D \\
\hline 550 & HEU SRS Solutions & 0.581 SHIPCUR & PACKAGED & STG AV & MOD R\&D & MODWR\&D \\
\hline 51 & SRS NU (Pu) Scrap & 0.574 SHIP.INC & PACK REQ & MIN MODS & MOD R\&D & MODWR\&D \\
\hline 524 & Pu Chlorides, flourldes etc & 0.566 SHIP.INC & PACK REQ & MIN MODS & MAJ R\&D & MODWR\&D \\
\hline 53.8 & Pu Combustibles & 0.552 SHIP.INC & PACK REQ & MIN MODS & MOD R\&D & NOWR\&D \\
\hline 54 & SRS DU Sludge and Filter Cake & 0.565 SHIPCUR & PACKAGED & STG AV & MOD R\&D & MODWR\&D \\
\hline 5 & SRS DU SS/Zr fuel/targets & 0.539 SHIPCUR & PACKAGED & STG AV & MOD R\&D & MODWR\&D \\
\hline 356 & SRṢ Pu/DU Oxide fuel rods & 0.539 SHIPCUR & PACKAGED & STG AV & MOD R\&D & MODWR\&D \\
\hline 57 & Np 237 scrap & 0.517 SHIP.INC & PACK REQ & STG AV & MAJ R\&D & MAJWR\&D \\
\hline 58 & SRŚ Pu/DU scrap & 0.489 SHIPCUR & PACKAGED & STG AV & MOD R\&D & 'MODWR\&D \\
\hline 59 & FMPC DU Nonburnable metal & 0.471 SHIP.INC & PACK REQ & MIN MODS & MOD R\&D & MODWR\&D \\
\hline C.60) & Pu-239 Pits & 0.457 SHIP. UN & FAC REQ & MAJ MODS & MOD R\&D & MODWRED \\
\hline 679 & FMPC DU lead contaminated & 0.410 SHIP.INC & PACK REQ & STG AV & MAJ R\&D & MAJWR\&D \\
\hline 6 & Metal U-Zr SNF & 0.338 SHIP. UN & FAC REQ & MAJ MODS & MAJ R\&D & MAJWR\&D \\
\hline 663 & Metal(U,U-Mo)/Na SNF & 0.338 SHIP. UN & FAC REQ & MAJ MODS & MAJ R\&D & MAJWR\&D \\
\hline .64 & Oxide-Research SNF & 0.310 SHIP. UN & NOT DET & MAJ MODS & MAJ R\&D & MAJWR\&D \\
\hline 6 & OxIdo-Commerclal SNF & 0.305 SHIP. UN & NOT DET & MAJ MODS & MAJ R\&D & MAJWR\&D \\
\hline 668 & OxIdo DIsrupted TMI SNF & 0.270 SHIP. UN & FAC REQ & MAJ MODS & MAJ R\&D & MAJWR\&D \\
\hline $67 \mathrm{~g}$ & Oxide, U/Th SNF & 0.000 & & & & \\
\hline 68 & FMPC Chips in concrete LEU & 0.000 & & & & \\
\hline 69 & SRS Vitriffed waste LEU & 0.000 & & & & \\
\hline 70 & FMPC DU chips In concrete & 0.000 & & & & \\
\hline 71 & Graphlte SNF & 0.000 & & & & \\
\hline 72 & Misc Other SNF & 0.000 & & & & \\
\hline 737 & Misc Other (falled) & 0.000 & & & & \\
\hline $74 ?$ & Irradlated Reactor Parts & 0.000 & & & & \\
\hline
\end{tabular}




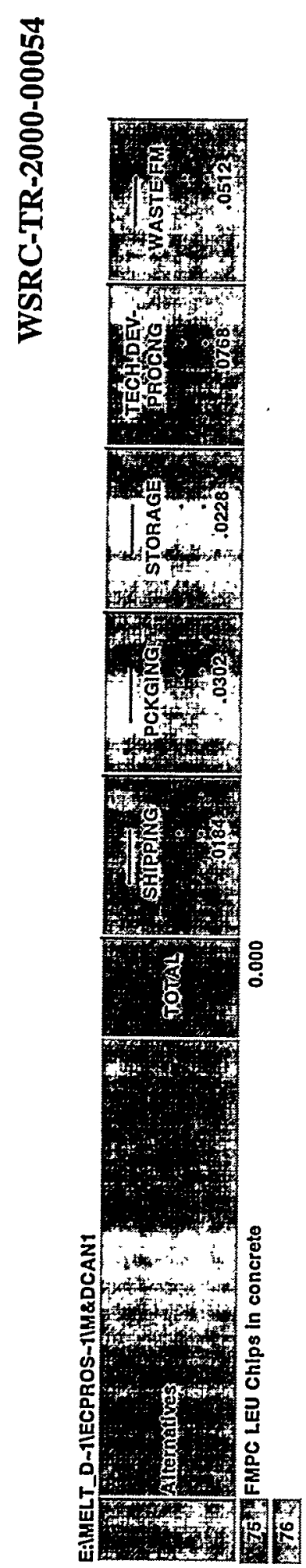


This page intensionally blank 